\title{
Empiric Approach for Criteria Determination of Remaining Lifetime Estimation of MV PILC Cables
}

\author{
I. Mladenovic and Ch. Weindl \\ Additional information is available at the end of the chapter
}

http://dx.doi.org/10.5772/51490

\section{Introduction}

Underground cables represent one of the biggest assets and investment demands of power utilities. In the same time they are the major source of faults and outages in medium voltage (MV) power networks. The oldest cable type, still present in a high percentage in today's MV power networks, is the paper insulated lead covered (PILC) cable. It was mainly laid in the period from 1920 to 1980, (Tellier, 1983), hereafter it has been systematically replaced by most distribution companies with thermoplastic polyethylene (PE) and finally cross-linked polyethylene (XLPE) cable types. Nevertheless, almost 95\% of the MV power cable networks of "NUON Infra Noord-Holland" are made up of PILC cables, (E. F. Steennis, R. Ross, N. van Schaik, W. Boone \& D.M. van Aartrijk, 2001), 65\% of the network of one of the biggest energy supplier in Belgium, 56\% in the urban areas in Bavaria (Germany), and ca. 50\% of entire MV cable network of Germany. At the end of $20^{\text {th }}$ century in Germany, as reported in (FGH - Forschungsgemeinschaft für Elektrische Anlagen und Stromwirtschaft e. V., 2006), there were more than $30 \%$ of cables over 30 years in service, and more than $15 \%$ over 45 years in field operation - almost all are PILC cables. Furthermore, this all corresponds to an cable network length of $110.000 \mathrm{~km}$ that consist only of cables which already have or soon will exceed the expected cable service life time of 40 years, and nearly 3,2 billion Euro of investments.

Within the years of service operation and especially when the predicted service lifetime is exceeded, the failure rate is expected to increase significantly. Sudden and unexpected cable failures mostly cause many incidental issues, additional costs and penalty payments. In order to optimize costs and to keep up or improve the reliability of the power system, more

The presented chapter is further discussed in Ph.D. thesis "Determination of the Remaining Lifetime of PILC Cables based on PD and tanઠ Diagnosticis," Mladenovic, 2012 
and more utilities and distribution companies decide for condition based asset management and maintenance strategies. A sophisticated knowledge of the components actual condition and an early detection and prediction of service failures are therefore the bases for an efficient planning of the maintenance strategy and the resulting investments. For this purpose various diagnostic systems are used, which are mostly based on the measurement of the partial discharge (PD) activity and/or other dielectric key values like e.g. the value of the dissipation factor $\tan (\delta)$ at different test-voltage levels.

Unfortunately, there are still no well-established and physically - founded substantial criteria which define e.g. the probability of the next failure versus the PD or $\tan \delta$-levels for defined test voltages and test conditions. Hence,for further improvements of diagnostic systems and the prediction of failure-times a correlation of the field measurement data and parameters acquired under well-known laboratory conditions is necessary together with a following reference setting and interpretation. This could further lead to the development of physically oriented ageing models correlating the cable's level of lifetime consumption and several measured diagnostic parameters, their dependencies and development. The complex mathematical models can only be derived on the basis of a fundamental databank including cable specification data, service operation profiles and numerous electrical and diagnostic parameters monitored during and representing the complete cable life cycle. In this way, the assumption of the remaining life time will be based on numerous diagnostic measurements and parameters. A restriction to regular measurements and failure-time data out of the field would last in a monitoring process over several decades and more or less undefined, unknown or less reliable measurement conditions caused e.g. by the various influences of the equipment's temperature and its gradients on diagnostic parameters.

On this background, a system for artificial and accelerated ageing of MV PILC cables has been developed and realized, (Mladenovic \& Weindl, Determination of the Characteristic Life Time of Paper-insulated MV-Cables based on a Partial Discharge and $\tan (\delta)$ Diagnosis, 2008) (Dr.-Ing. Weindl \& Dipl.-Ing. Mladenovic, 2009) (Mladenovic \& Weindl, ICAAS Integrated System for lasting Accelerated Aging of MV Cables, Data Monitoring and Acquisition, 2009) (Mladenovic I., 2009). The ICAAS (Integrated Cable Accelerated Ageing System) facilitates a realistic $(50 \mathrm{~Hz})$ but accelerated ageing by applying pre-defined and concurrent thermal and electrical stressconditions with a highly sensitive and selective PDdetection and $\tan \delta$ measurement. By controlling the technical and environmental conditions of the artificial ageing processes the ageing rapidity can be modified and increased. During the ageing experiment, a daily monitoring of the cable samples was realized by measuring the diagnostic parameters under pre-defined conditions and selective for each individual cable sample, (Freitag, Weindl, \& Mladenovic, On-Line Cable Diagnostic Possibilities in an Artificial Aging Environment, 2011) (Freitag, Mladenovic, \& Weindl, Fully Automated MV Cable Monitoring and Measurement System for Multi-Sample Acquisition of Artificial Aging Parameters, 2010). Moreover, the entire accelerated ageing process, all systemparameters and internal signals are monitored in close-meshed time intervals. Using a suitable set of pre-aged cabled samples, an ageing database of over 800GB was formed up that enables statistical approaches to determine the actual and integral ageing factor, the characteristics of the ageing process, the key ageing parameters, as well as their limits. 
Once the databank is formed-up and before the statistical analysis is applied, there is a necessity to discuss the physical dependencies of the relevant electrical properties on the environmental and test conditions and the ageing process of the paper-mass insulation system. Herby, the structure and the chemical background of the insulation components of the PILC cables will be shortly presented, and the way it could influence the ageing rapidity, the development of partial discharges and the thermal breakdown. The discussion of the behavior of the relative permittivity $\left(\varepsilon_{r}\right)$ and conductivity $(\kappa)$ with varying temperature and humidity, voltage and frequency as well as the influence of the impurities, cavities and bubbles presence on the electrical properties and ageing of the insulation material will follow. Hence, the main dependencies of the diagnostic parameters and their development can be explained, (Mladenovic \& Weindl, Determination of the Characteristic Life Time of Paper-insulated MV-Cables based on a Partial Discharge and $\tan (\delta)$ Diagnosis, 2008) (Mladenovic \& Weindl, Dependencies of the PD- and $\tan (\delta)$-Characteristics on the Temperature and Ageing Status of MV PILC Cables, 2011) (Mladenovic \& Weindl, Dependency of the Dissipation Factor on the Test-Voltage and the Ageing Status of MV PILC Cables, 2011) (Mladenovic \& Weindl, Development of the Partial Discharges Inception Voltage for Different Sets of Pre-Aged PILC Cable Samples, 2010) (Mladenovic \& Weindl, Influence of the thermal stress on the diagnostic parameters of PILC cables, 2010).

The approach presented here, the entire ageing experiment, the data analyses and conclusions are systematically elaborated in (Weindl, Verfahren zur Bestimmung des Alterungsverhaltens und zur Diagnose von Betriebsmitteln der elektrischen Energieversorgung, 2012) Mladenovic, Ph.D., Determination of the Remaining Lifetime of PILC cables based on PD and $\tan (\delta)$ diagnosis, 2012, to be published) (Freitag, Ph.D., to be published).

\section{Insulation system of PILC cables}

The insulation system of PILC cables is a complex and inhomogeneous structure of mass impregnated paper layers. During the operation, the electrical field is distributed so that the thin mass layers overtake a bigger part of the electrical field strength. The paper will keep the separation distance and will be a barrier to the impurities from layer to layer. An insulating paper (e.g. kraft paper consists of about $90 \%$ of long-chained macromolecules, Figure 1) i.e. cellulose fibrils, is formed by the polymerization of the glucose molecules. Cellulose molecules arranged in fibrils have an immense tensile strength.

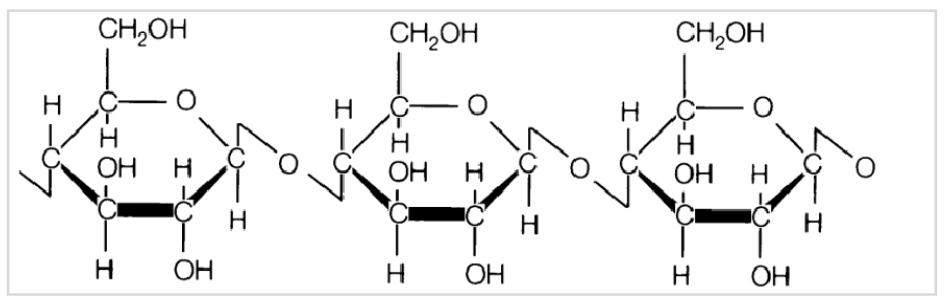

Figure 1. Cellulose molecule (C6H10O5)n, (Colebrook) 
The length of the cellulose chains defines the degree of polymerization (DP), the number of glucose units that make up one polymer molecule:

$$
D P=\frac{\text { molecular weight }}{\text { molecular weight of base unit }}
$$

Properties of the cellulose and therefore paper are strongly dependent on DP.

For example, a new insulation paper has a DP of 1100-1300, which decrease with the operation time or ageing, reducing as a consequence the mechanical strength of the paper. A DP of less than 500 indicates significant thermal degradation, and finally, a DP of 200 is concerned as the limit of the mechanical strength and end of paper life, (Küchler, 2009), since weakening of mechanical properties could lead to e.g. cable failure during short circuits.

The structure of the impregnating compound was changed over the decades of manufacturing PILC-cables. At the beginning of 20th century, mineral oils have been used, followed by oil-rosin up to lastly non-draining (non-migratory) compounds in the time before World War II, (Bennett, October 1957). This poly-isobutylene compound - MIND (mass-impregnation with non-draining compound) held up to today. It presents the differently proportional mixtures of natural or synthetic resin, paraffin, bitumen and oil, (www.wikieduc.ch, 2010). Beside it is much more practical for handling; process of oxidation in MIND compound is much more slowly than in insulating oils. Also its dielectric loss angle $\delta$ is less dependent on the temperature. One of its disadvantages, as given in (Bennett, October 1957), is that brand new cables could contain numerous voids, due to the high expansion coefficient of the material. Also, the compound retains its nondraining properties up to $70^{\circ} \mathrm{C}$, nowadays improved to $90^{\circ} \mathrm{C}$, or even $100^{\circ} \mathrm{C}$, (Kock \& Strauss, 2004).

\section{Ageing mechanisms of mass-impregnated paper}

During the operation, the insulation of the PILC cables is exposed to numerous effects like temperature, electrical field, moisture presence (invasion), mechanical stress, which causes over the time steady insulation degradation. Herby, the paper presents the weaker component, and it's therefore the main cause of the insulation ageing. As presented in (Bennett, October 1957) the degradation of the mass is an oxidative and slow process. Moreover, oxygen presence in the cable insulation is not worth of consideration differing it from the oil insulation in transformer. There are several mechanisms of the impregnated paper degradation like hydrolytic, oxidation, thermal and electrical degradation (Emsley \& Stevens, 1994). In Figure 2 the degradation of cellulose is shown.

During field operation, there is a regular thermal degradation of the components insulation. The maximal nominal operating temperature of the $12 / 20 \mathrm{kV}$ three core PILC cables is $65^{\circ} \mathrm{C}$, (Glaubitz, Postler, Rittinghaus, Seel, Sengewald, \& Winkler, 1989). Temperatures in the range lower than $200^{\circ} \mathrm{C}$, in the absence of oxygen and moisture tends to open glucose rings 
and break the glycosidic bonds. Finally, it results in free glucose molecules (decrease of DP) and release of moisture, carbon monoxide and carbon dioxide, as shown in Figure 2. Additional presence of moisture again accelerates the process of cellulose decomposition. If the temperature would exceed $200^{\circ} \mathrm{C}$, other reactions would occur, including even destruction of the solid components.

Moreover, gasses formed through the thermal degradation would fill the cavities (if there), presenting in this way an electrical weakness within the insulation and a potential PD source. An increase of the electrical stress would intensify PD activity producing additional gases in the locally heated area, leading further to the expanding of weak region. However, this chain process can also be interrupted by voids migration or by the voids refilling with the mass, as soon as the mass viscosity reaches a necessary value and it moves under the pressure caused by a temperature increase. The process of "moving" or "disappearing" PD sources makes the diagnostic of the PILC cables based on PD very complex, unreliable and incomplete.

a) Thermal Degradation, $\mathrm{T}<200^{\circ} \mathrm{C}$

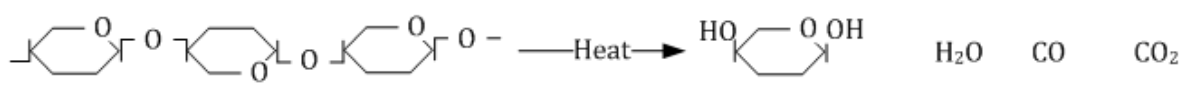

Breaks glycosidic bonds and opens glucose rings

b) Oxydative Degradation

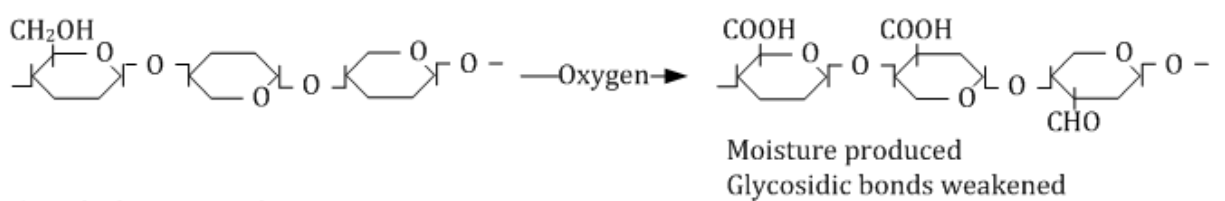

c) Hydrolytic Degradation

Glycosidic bonds weakened

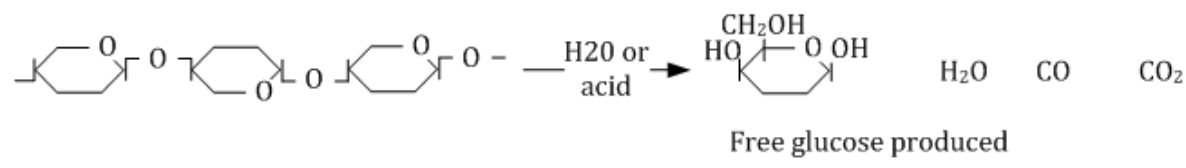

Figure 2. Degradation of cellulose (Unsworth \& Mitchell, 1990)

The presence of moisture leads to hydrolysis, the most dominant degradation process, where chemical connections are divided through the influence of water. Moisture could penetrate the insulation due to mechanical damages in the lead sheath, or it is a self-product of cellulose degradation through the other degradation processes, initiating in this way a chain reaction. This process could be additionally accelerated by higher temperatures. According to (Glaubitz, Postler, Rittinghaus, Seel, Sengewald, \& Winkler, 1989) the maximal allowed short circuit temperature of three core PILC cables is $155^{\circ} \mathrm{C}$. Therefore, the temperatures that could lead to the pyrolysis of the cellulose are not common in the field. In 
(Emsley \& Stevens, 1994) the chemical mechanisms of low-temperature $\left(<200^{\circ} \mathrm{C}\right)$ degradation of cellulose is thoroughly described.

Moreover, through the transients, short circuits or load variations in field operation, the cable temperature could vary and change very suddenly. As it was shown in (Soares, Caminot, \& Levchik, 1995) there is no influence of the temperature increase (heating rate) on activation energy; it was opined that thermal decomposition of the kraft paper mostly proceeds through steady depolymerisation. Anyway, hydrolytic degradation is the most powerful degradation in cellulose, and due to the moisture outcome it could be initiated by both, thermal or oxidative degradation.

Obviously, ageing is a complex chain cause-reaction-cause process. Summarized, it results in the decrease of DP, increase of moisture content, and appearance of different gasses, resulting in the changing of electrical and mechanical properties of the insulation system.

\section{PILC cables - Diagnostic methods}

Diagnostic methods are nondestructive measurements of the dielectric properties in the purpose of a condition determination. Among electrical diagnostic methods, which refer to the behavior of the insulation in an electrical field, there are also chemical diagnostic methods, optical, acoustical, magnetic, mechanical, etc. defined in several standards (e.g. (High-voltage test techniques - Partial discharge measurements, 2000) (High voltage test techniques - Measurement of partial discharges by electromagnetic and acoustic methods "Proposed Horizontal Standard", 2011)). Electrical diagnostic methods of PILC cables could be divided in two main groups dependent on the type of applied voltage, AC or DC as shown in Figure 3. Measurements of cable performance with an AC test-voltage are Partial Discharge (PD), Oscillating Wave Test System (OWTS) and tan $\delta$ measurements, where measurements of PDs and $\tan \delta$ are usually performed by $0,1 \mathrm{~Hz}$ (Very Low Frequency (VLF) (IEEE Guide for Field Testing of Shielded Power Cable Systems Using Very Low Frequency (VLF), 2004)), and in some cases at $50 \mathrm{~Hz}$. Besides, some diagnostic measurements of $\tan \delta$ like e.g. Frequency Response Analyses (FRA) operate in a wide range of frequencies, (Neimanis \& Eriksson, 2004). The DC methods are based on the analyses of the diagnostic properties in time domain, (Mladenovic, Determination of the Remaining Lifetime of PILC cables based on PD and $\tan (\delta)$ diagnosis, 2012, to be published), like in e.g. return voltage measurement (RVM), polarization/depolarization current measurement (PDC) and the less used Decay Voltage Method (DVM) and Isothermal Relaxation Current (IRC).

The only measurement with a local character are measurements of partial discharges, means it can localize the fault in progress, but it does not give the information about the general insulation condition. In (Densley, 2001) diagnostic tests for PILC cable system with their advantages and limitations are listed.

It has to be also mentioned, that a direct comparison of the values measured under different test-conditions e.g. ambient temperature, or even with different diagnostic systems is not always plausible. In any case, the results of the different diagnostic measurements are more 
or less complementary to one other and summarized could deliver more complete and more reliable information about insulation condition.

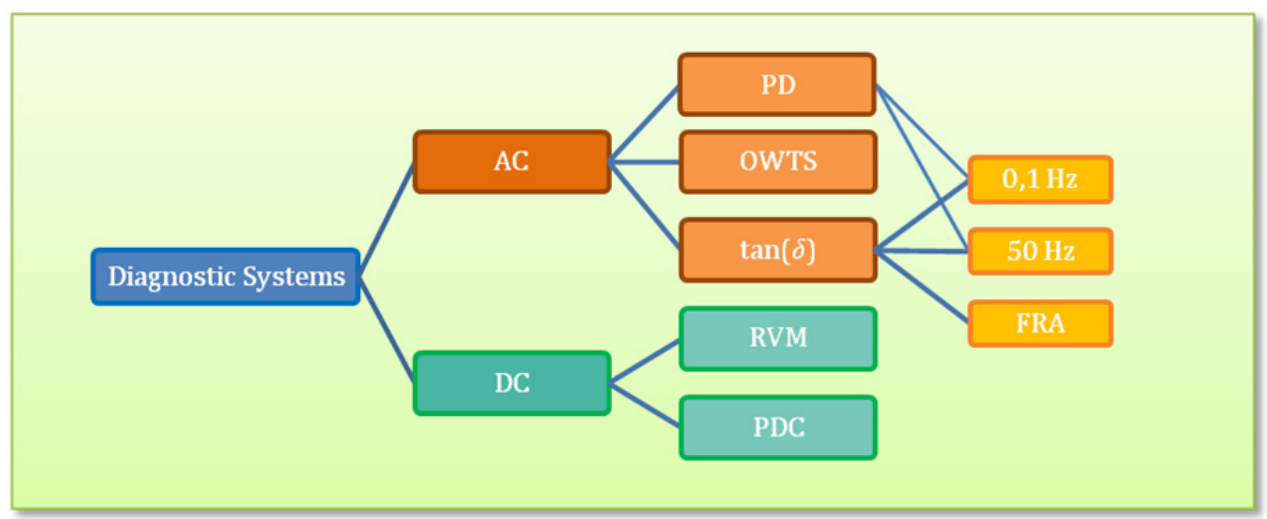

Figure 3. Principal overview of diagnostic systems for power cable

\subsection{Dielectric losses and dissipation factor}

The dissipation factor is the tangent of the loss angle defined as the phase shift between leakage current and the applied test voltage to $90^{\circ}$.

Losses in the dielectric are caused by the moving of the charges under the influence of applied electrical field. The real losses $\left(P_{\delta}\right)$ are determined through the current component $I_{\delta}$ and the reactive power $\left(Q_{c}\right)$ through the component $\underline{I}_{c}$, Figure 4 . Thus, dissipation factor $\tan \delta$ could be determined as:

$$
\tan \delta=\frac{P_{\delta}}{Q_{c}} .
$$
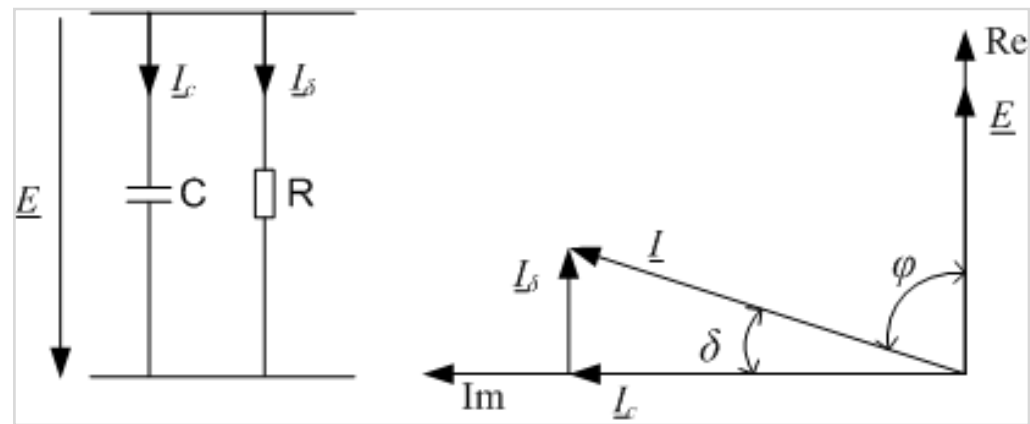

Figure 4. Simplified equivalent circuit and vector diagram of a real dielectric 
Hereby two kinds of losses could be defined: polarization losses and losses due to the conductivity:

$$
\tan \delta=\frac{\kappa+\omega \varepsilon_{0} \varepsilon_{r}^{\prime \prime}}{\omega \varepsilon_{0} \varepsilon_{r}^{\prime}}=\tan \delta_{c o n}+\tan \delta_{p o l},
$$

where:

$$
\tan \delta_{\text {con }}=\frac{\kappa}{\omega \varepsilon_{0} \varepsilon_{r}^{\prime}}
$$

and

$$
\tan \delta_{p o l}=\frac{\varepsilon_{r}^{\prime \prime}}{\varepsilon_{r}^{\prime}} .
$$

Assuming a very low value of the dissipation loss angle $\delta$ and regarding to (3) it can be approximated that:

$$
\delta=\delta_{c o n}+\delta_{p o l} .
$$

It is important to mention that if there is some PD activity within the dielectric, it will cause additional losses:

$$
\tan \delta=\tan \delta_{c o n}+\tan \delta_{p o l}+\tan \delta_{P D}
$$

Analog to (6), it can be approximated:

$$
\delta=\delta_{c o n}+\delta_{p o l}+\delta_{P D}
$$

\subsection{Partial discharges}

Partial discharges are gas-discharges of Townsend type and streamers which occur under specific conditions in gas filled cavities within the insulation. The presence of the cavities leads to a local change of the electrical permittivity and conductivity, disturbing the homogeneity of the electrical field and therefore to a decrease of electrical stability.

Exposed to an electrical AC field a random ionization process within the cavity will start, which produces a free 'start' electron needed for the development of PD. The electrical field forces the electron moving to the (local) anode within the void, ionizing on the way more gas atoms and producing therefore positive ions and more electrons. In this way the ionization events multiply causing the start of an electron avalanche. These are called 
Townsend discharges. In the same time a cloud of positive ions, which are heavier and therefore slowly, moves towards the cathode, tending to reduce the cavity voltage under its breakdown value. If the voltage increases more Townsend discharges will occur again, means if the sinusoidal voltage continues to increase exceeding again the breakdown voltage of the gas, new discharge will occur to stabilize the cavity voltage. The process of charge transferring will begin tapering off near the breakdown voltage. Townsend discharges predominantly occur between paper layers and within the butt gaps, (Mladenovic, 2012, to be published), (Robinson, 1990).

On the other hand, if the applied voltage is high enough and the cavity is of enough depth so that the mean free path of the electrons is shorter than the distance between the electrodes, Townsend avalanches can develop into stream-discharges. If one start-electron creates the avalanche of $10^{6}$ up to $10^{8}$ electrons, it will come to a change of the electrical field in the surrounding area, since the heavier positive ions remain at the avalanche-tail while the electrons form the tip of the streamer. Through the enhanced electrical field and space charges on the avalanche-tip it will come more rapidly to new avalanches and more photons, accelerating the charge transfer regardless to the reduction of the cavity voltage. If the producing of the free electrons trough the impact ionization is faster than the electron summation, a conducting channel within the cavity will be formed and the transfer will stop as all the charges stored on the faces of the cavity are transferred, i.e. cavity voltage drops to zero, (Küchler, 2009) (Robinson, 1990).

Even fewer in number, single streamers could cause the bigger damage to the insulation (paper) due to the higher released energy. "The tip of the streamer has a radius of the order of tens of micrometers and the concentration of energy within the dimension results in penetration of the paper layers by pinholes", (Robinson, 1990). Moreover, in (Lemke, 2008) PDs are classified as: "the pulse charge created by glow discharges, oft referred to as Townsend discharges, is usually in the order of few pC. Streamer discharges create pulse charges between about $10 \mathrm{pC}$ and some $100 \mathrm{pC}$. A transition from streamer to leader discharges may occur if the pulse charge exceeds few 1000pC". Dependent on the intensity and the repetition rate of the local breakdowns, its surrounding within the dielectric could be "infected" and thus the weak area could expand, finally leading to the breakdown of the complete dielectric.

Beside the strength of applied voltage, relevant for the occurrence and sustain of these discharges, i.e. partial discharges, is the voltage frequency and insulation temperature. The nature of the discharges, its detection, PDs damaging power and insulation degradation exposed to PD activity, detection and measurement of PD, their intensity, repetition rate, etc. are systematically presented e.g. in (Niemeyer, 1995) (Bartnikas, 2002).

Partial discharges are defined in IEC 60270 as: "localized electrical discharges that only partially bridge the insulation between conductors and which can or cannot occur adjacent to a conductor. Partial discharges are in general a consequence of local electrical stress concentrations in the insulation or on the surface of the insulation. Generally, such discharges appear as pulses having duration of much less than $1 \mu \mathrm{s."}$ 
Gas filled cavities, locally increased moisture content; impurities within the dielectric, rifts, etc. are all classified as local weakness. A consequence of their presence is a local decrease of the relative permittivity which results in the decrease of a local breakdown voltage. In Figure 5 a gas filled cavity within a dielectric and its equivalent circuit are shown. $C_{1}$ is the capacity of the cavity with relative permittivity $\varepsilon_{r 1}, C_{3}$ and $C_{2}$ are inner dielectric capacities with relative permittivity $\varepsilon_{r}$.

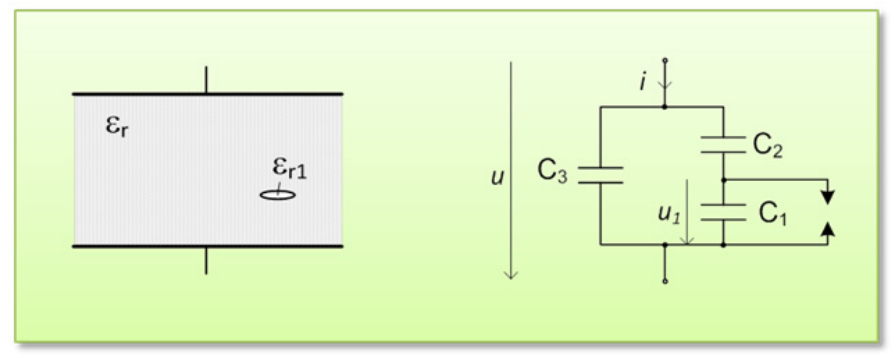

Figure 5. Equivalent circuit of the cavity within the dielectric and PD activity

Here $u_{1}$ is indicated as the breakdown voltage of the cavity. If, by applying an ACvoltage $u$, the voltage over capacitance $C_{1}$ exceeds ignition voltage $u_{1}$, the capacity will discharge as symbolically shown in Figure 5 over spark gap. This process will repeat with the frequency $40 \mathrm{kHz}-1 \mathrm{MHz}$ (up to $10 \mathrm{MHz}$, (Kuhnert, Wieznerowicz, \& Wanser, 1997)), as long as the absolute value of the voltage over $C_{1}$ is higher than the ignition voltage of the void, and it can be notified as discharge pulses in the measured current $i$. Theoretically, PDs are essentially Townsend discharges, although their form and some features could vary as shown in (Bartnikas, 2002). However, in the praxis, measurement systems concern pulse-type discharges, their inception voltage, intensity, repetition rate i.e. frequency, etc. Generally, for an insulation material it can be stated that PD activity could cause progressive deterioration and cause irreversible mechanical weakening through chemical reactions and physical changes, (Mladenovic, Determination of the Remaining Lifetime of PILC cables based on PD and $\tan (\delta)$ diagnostics, 2012, to be published).

However, in the complex insulation systems like PILC cables, or oil cables, the effect of selfhealing is well known and refers to the e.g. oil/mass refilling of the cavities, or cavities displacing. Still, if PD occurs between the paper layers, they could punctures it, (Robinson, 1990), causing irreparable chemical changes which will influence the surrounded material by exposing it to an increased electrical stress, heating, and so on, until the further carbonization and break down, (Stanka, 2011). In (Bartnikas, 2002), the mechanism and nature of PD is well elaborated, and its detection and measurement systems are chronologically shown and discussed, since first reported measurement methods in 1933.

The measurement or rather detection of these pulses can be done using electrical, mechanical, optical and chemical methods, (High voltage test techniques - Measurement of partial discharges by electromagnetic and acoustic methods "Proposed Horizontal 
Standard", 2011). The PD measurements applicable on the MV and HV cables are based on the electrical detection methods, which are shown in (High-voltage test techniques - Partial discharge measurements, 2000). For diagnostic purposes, the most appropriate are the measurements on the nominal frequency of $50 / 60 \mathrm{~Hz}$. In this way measured inception voltage or PD intensity etc. corresponds to those during normal network operation. Hereby measurements are commonly run on different voltage levels, for example 1, 1,3, 1,7, 2, and 2,5 times the line to ground voltage. Beside $50 / 60 \mathrm{~Hz}$ measurement systems, there are diagnostic systems operating on $0,1 \mathrm{~Hz}$, and so-called Oscillating Wave Test System (OWTS) presented in (Petzold \& Zakharov, 2005), (Petzold \& Gulski, 2006). Newly, many researches and developments are directed to the improving of on-line PD measurements, (A. N. Cuppen, E. F. Steennis, \& P. C. J. M. van der Wielen, 2010) (P. A. A. F. Wouters, P. C. J. M. van der Wielen, J. Veen, P. Wagenaars, and E. F. Steennis, 2005) (Boltze, Markalous, Bolliger, Ciprietti, \& Chiu, 2009) (Tian, Lewin, Wilkinson, Sutton, \& Swingler) (Ambikairajah, Phung, Ravishankar, Blackburn, \& Liu, 2010).

Finally, presence of PD could accelerate the ageing rapidity hardly and shorten the remaining lifetime of the insulation material, (Robinson, 1990). However, also for the purpose of the interpretation of the PD measurements, there are still no classifications or criteria, and hence the correspondence between PD activity levels and recommended actions. Nevertheless, beside PD magnitudes numerous other related and derived PD quantities are considered for the data interpretation, (Lemke, 2008): PD Inception Voltage (PDIV), PD Extinction Voltage (PDEV), PD magnitudes on different voltage levels, PD repetition rate, PD repetition frequency, phase angle, average discharge current, discharge power, etc. Due to the numerous still unknown influencing factors on the PD activity, the physical interpretation of the measured data is still a very complex process. For example:

- $\quad$ the number of pulses and their amplitudes vary from half-cycle to half-cycle.

- The PD repetition rate per second should increase with a rising of the test-voltage. It could also indicate the size of the source cavities, since small voids yield to very few PD pulses per half-cycle until the number increase with cavity size.

- $\quad$ The temperature, i.e. pressure increase in the cavity could yield to extinguishing of PD activity.

Finally, it is given in (High Voltage - VLF Hipot Instruments): "There is no reliable consensus on what are good versus bad PD levels. Splices can exhibit very high levels of partial discharge yet last for years, while those showing lower PD levels might fail sooner. One must keep in mind what the purpose of the test is. Whether using partial discharge or $\tan \delta$ techniques, the point of the test is to grade all cables tested on a scale from high quality to low".

\section{Dependencies of the diagnostic parameters}

The structural dependencies of the $\tan \delta$, the relative permittivity $\varepsilon_{r}$ and the conductivity $\kappa$ are shown in Figure 6. A temperature increase results in an increase of the mobility of the 
(polarized) molecules, the charge carriers and the number of electrons having at least the necessary energy to overcome the potential barrier or in other words the activation energy $E_{a}$, (Küchler, 2009). Therefore, there is a constant rise of conductivity, (Bayer, Boeck, Möller, \& Zaengl, 1986):

$$
\tan \delta_{\text {con }}=\mathrm{Ae}^{-E_{a} / \mathrm{k} T}
$$

where are: A - the pre-exponential factor, $T$ is the absolute temperature and k Boltzmann constant.

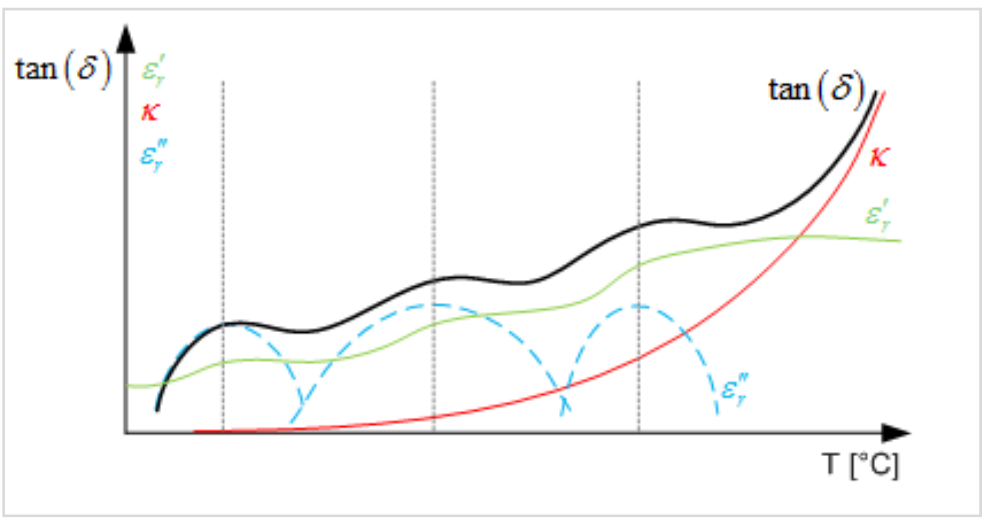

Figure 6. Structural dependencies of the dissipation factor $\tan \delta$, relative permittivity $\varepsilon_{r}$, and conductivity $\kappa$ on temperature with three different polarization mechanisms (dashed blue line)

On the other hand, the polarization processes show different resonant phenomena over a wider temperature range. Appropriate temperatures drive different polarization processes. Even one polarization process like the orientational polarization can have e.g. two resonant temperatures due to the presence of different molecular structures, like e.g. moisture in the paper-mass insulation system. Therefore, with an increasing temperature the relative permittivity rises stepwise at discrete temperatures as a consequence of increased dipole mobility. Finally, with higher temperatures $\varepsilon_{r}$ decreases again due to the thermal agitation which results in a partial disorganization of the dipole arrangements caused by the field. The activity of PD, if any, will change according to ideal gas and Paschen's law, (Mladenovic, Determination of the Remaining Lifetime of PILC cables based on PD and $\tan (\delta)$ diagnostics, 2012, to be published). Also, conductive channels within insulation, if present, will develop faster leading to the complete breakdown of the insulation.

Since the temperature cannot be adjusted in field measurements, the temperature dependency of tan $\delta$ is inappropriate to be used as a diagnostic criteria directly. Although, it is very important to know its characteristic behavior for different ageing situations and to have reference $\tan \delta$-temperature-condition profiles, so that the measured parameters can be evaluated correctly. According to (Bayer, Boeck, Möller, \& Zaengl, 1986) the $\tan \delta$ of MV 
PILC cables (viscosity of $50 \mathrm{~mm}^{2} / \mathrm{s}$ by $100^{\circ} \mathrm{C}$ ) reaches its maximum in the vicinity of $-8^{\circ} \mathrm{C}$ and the minimum in the region of $30^{\circ} \mathrm{C}$. It was shown and discussed in (Mladenovic \& Weindl, Influence of the thermal stress on the diagnostic parameters of PILC cables, 2010) that temperatures around $30^{\circ} \mathrm{C}$ are also not optimal for diagnostic measurements of MV PILC cables based on the dissipation factor.

Unlike to the temperature, the test voltage can be adjusted and is therefore used as a parameter for some diagnostic methods. According to equation (1), the differential $\tan (\delta)$ values- $\Delta \tan \delta$ measured at two times the nominal voltage $U_{2}$ and the nominal voltage $U_{1}$ are partially used for this purpose.

Theoretically, it is to be expected that the dissipation factor raises with an increase of the voltage since these means an injection of more energy, enhancing the energy of the charge carriers and a multiplication of the ions. Therefore, the conductivity and in this way the $\tan \delta$ is principally rising with increasing test voltages. It was shown in (Bayer, Boeck, Möller, \& Zaengl, 1986) on the example of epoxy resin, that $\varepsilon_{r}$ increases with rising test voltages, and that the gradient is steeper for higher temperatures.

The dominating ageing process in paper-mass insulation systems is a degradation of the cellulose which results in a higher moisture content. Since the conductivity and permanent resistivity of the water is much higher than of cellulose-mass it can be expected that cables with higher moisture content show stronger dependency of the $\tan \delta$ on voltage.

The behavior of PD activity with varied test-voltage is already well known and widely used as a diagnostic criterion for the detection of numerous failures that can occur in cables and cable garnitures.

Moreover, a stepwise increase of the dissipation factor with the test-voltage is often interpreted as a result of increased PD activities within the insulation. Anyway, the rate of the losses caused by PD activity in the total dissipation losses is very indistinct, since it is defined by the cable length, the number of weaknesses, the PD intensity, etc., (Mladenovic \& Weindl, Comparison of the parametric Partial Discharges and Dissipation factor Characteristics of MV PILC Cables, 2012).

\section{Artificial ageing experiment}

For a successful development of reliable ageing models, it is of prime importance to have different but constant ageing conditions and access to the regularly measured and monitored parameters up to the failure events. Therefore the characteristic key-values of the $\mathrm{PD}$ and $\tan \delta$ were acquired selectively for each cable at least daily over the complete artificial ageing period of two years. Beside the main field of thermo-electrically aged cable samples, selected cables were set under thermal stress only, while another group cables was electrically aged. In this way it should be possible to determine the parameters in the ageing models and the influence of each stress type on the ageing rapidity. The thermal ageing can principally be modeled by Arrhenius law, the electrical ageing by e.g. the inverse power law. When concurrent stress conditions are applied combined and complex ageing models 
have to be developed and analyzed. In addition, the Weibull distribution function is fitted to the fault behavior or measurement data characteristics. Therefore, the most probable lifetime, i.e. the most probable time to the next failure and its dependency on the values of the diagnostic parameters, load conditions or cable temperatures can be evaluated.

\subsection{Functional principle of ICAAS}

As part of the project, thoroughly described in (Weindl, Verfahren zur Bestimmung des Alterungsverhaltens und zur Diagnose von Betriebsmitteln der elektrischen Energieversorgung, 2012), the fully automated and Integrated Cable Accelerated Ageing System (ICAAS), incorporating a realistic accelerated ageing model, was developed, Figure 7. It involves voltage and current generation, $\mathrm{PD}$ detection and measurement, $\tan \delta$ measurement, as well as some other diagnostic parameters (Dr.-Ing. Weindl \& Dipl.-Ing. Mladenovic, 2009) (Mladenovic \& Weindl, IEEE Electrical insulation Magazine, 2012). Artificial ageing and diagnostic measurements are performed on each cable sample with nominal line-to-line voltage $U_{n}=20 \mathrm{kV}$ and nominal current of $I_{n}=239 \mathrm{~A}$. In order to ensure realistic accelerated ageing processes, the ageing and measurements were made under conditions comparable to normal service conditions at 50 or $60 \mathrm{~Hz}$ (IEEE Trial-Use Guide for Accelerated Aging Tests for Medium-Voltage Extruded Electric Power Cables Using WaterFilled Tanks, 1998), ("IEEE Guide for Field Testing and Evaluation of the Insulation of Shielded Power Cable Systems, 2001).

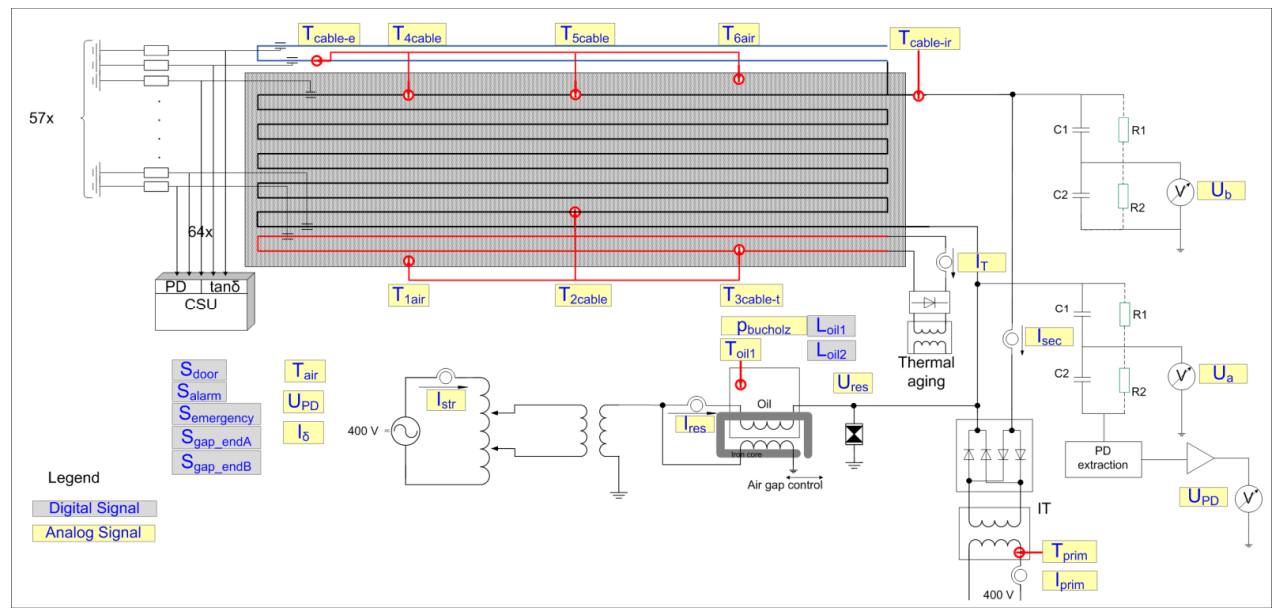

$\mathrm{T}_{\text {1air, }} \mathrm{T}_{\text {6air, }}, \mathrm{T}_{2 \text { cable, }} \mathrm{T}_{4 \text { cable }}$ and $\mathrm{T}_{5 \text { cable }}$ are temperatures within the thermal tank. $\mathrm{T}_{\text {cable-e }} \mathrm{T}_{3 \text { cable-t }}$ are the temperatures of electrically and thermally aged cables respectively, and $\mathrm{T}_{\text {cable-ir }}$ is the temperature of the termination. $\mathrm{T}_{\text {prim, }} \mathrm{T}_{\text {oil }}$ and $\mathrm{T}_{\text {air }}$ are respectively the temperatures of the primary windings of the current generating transformer, the oil and the air. Istr, Ires, $I_{\text {prim }}$ and Isec are respectively the controlling currents in the autotransformer, the resonant circuit, and the primary and secondary sides of the current generating transformer. UPD and $I_{\delta}$ are respectively the diagnostic currents through the insulation. $U_{a}$ and $U_{b}$ are (redundant) ageing voltages measured by the voltage divider.

Figure 7. Simplified structure of the ICAAS ageing, measurement and control system 
Since most of the system components are highly specialized, and therefore rather expensive or not available on the market, almost all of the ICAAS system was designed and built in the Institute's laboratories. Voltages of up to four times the nominal operating voltage, and currents large enough (up to $500 \mathrm{~A}$ rms) to heat the cable conductors to the desired temperatures above $100{ }^{\circ} \mathrm{C}$, have to be generated by the developed ageing system. The voltage generation is bases on a resonant system (Figure 8). The series resonant circuit consists of the cable capacitance and a purpose-developed variable inductance coil with more than 3000 windings in more than 20 layers, and its inductance range up to $580 \mathrm{H}$, Figure 9 .

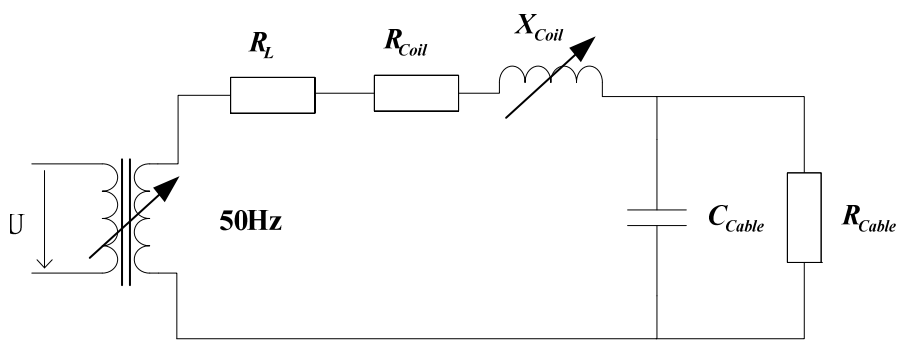

Figure 8. Structure of the voltage generating resonant circuit

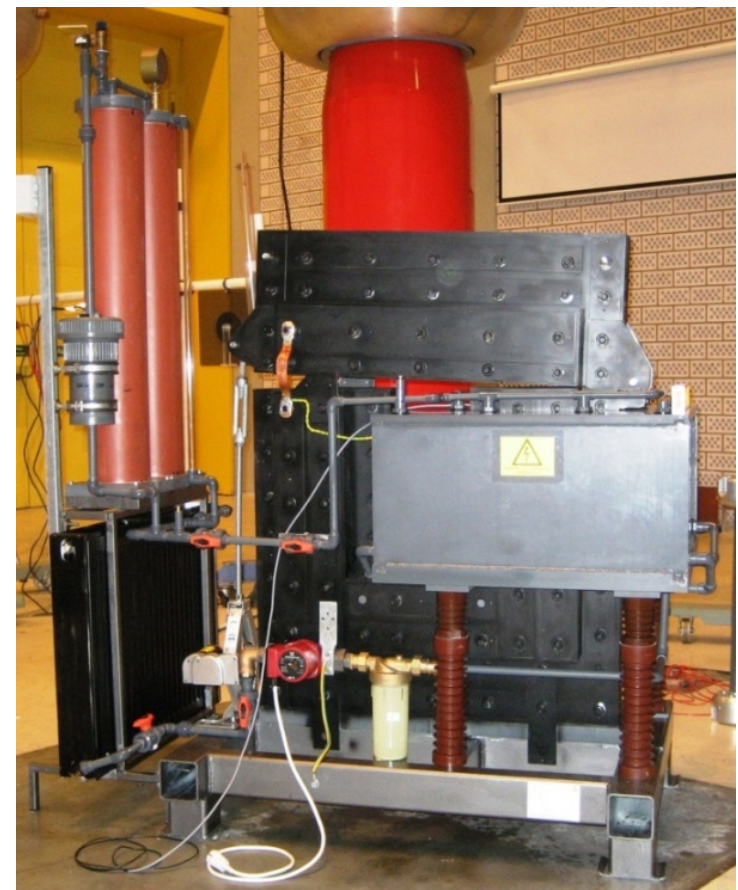

Figure 9. The resonant coil - a key ICAAS component 
Other requirements of the resonance circuit are a duty cycle of $100 \%$, exceeding the specifications of many of the standard test systems on the market, and absence of partial discharge up to approximately $50 \mathrm{kV}$.

The conductor current is generated using a custom-made pulse-width-modulated high current transformer, with an adequate electrical strength between the primary and the secondary side connected to the cable samples. In this way the ageing voltages up to $50 \mathrm{kV}$ can be applied in parallel. Preselected voltage profiles and defined load patterns, as well as other technical parameters, are controlled by a custom-built measurement and control system. In Figure 7 some of the main analog values which are measured, controlled and saved in pre-defined time intervals are shown in yellow, while the digital signals are shown in grey. In order to record all the necessary data and to control the ageing conditions, a Supervisory Control and Data Acquisition (SCADA) system was designed and developed (Freitag C., Entwicklung und Implementierung eines Steuerungs-, Regelungs- und Messsystems zur Realisierung einer automatisierten Versuchsanlage für die beschleunigte Alterung von Mittelspannungskabeln, 2008). It handles more than 100 analog/digital input/output values.

\subsection{Selection of cable samples and ageing parameters}

After the realization of ICAAS the first 24 installed cable samples were used within an pretest lasting for 6-9 months, in order to check and adjust the operation of the ageing and measurement systems, and to point out the most appropriate ageing conditions.

The test field was made up of nearly 100 PILC cable samples, with a nominal voltage $U_{n}$ of $20 \mathrm{kV}$ and a length of $13,5 \mathrm{~m}$, which were arranged in selective and representative agegroups. Most of the cables that were investigated had been in service for times between 20 and 60 years. Others were brand new or had been stored for 10 years. In Figure 10 cables stored in the ICAAS thermal tank, installed and prepared for the artificial ageing are shown. Up to 64 samples can be artificially aged and monitored simultaneously.

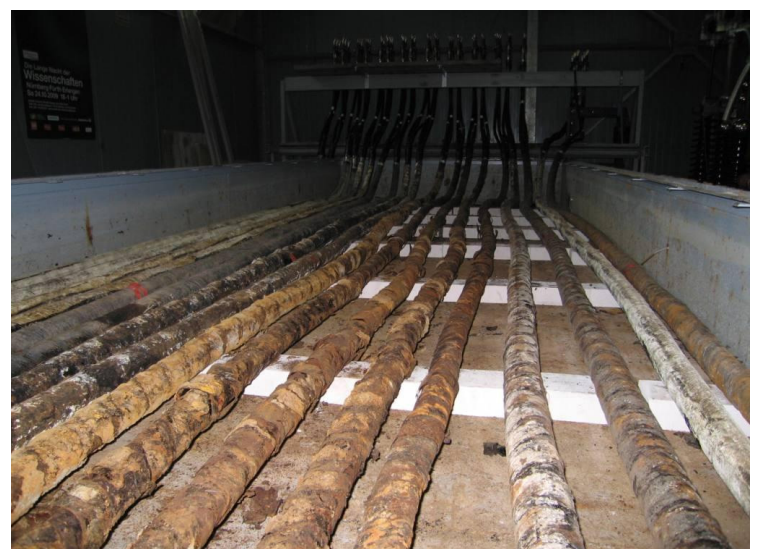

Figure 10. Cable samples in the thermal tank of the ICCAS system 
On the other hand, an inappropriate choice of the ageing conditions could result in too rapid ageing, caused perhaps by physical and chemical processes within the insulation system which do not occur under normal field operation. Thus, too high ageing currents and too high conductor temperatures could cause abnormal degradation of the paper insulation (cellulose) of the cables. Also, too low ageing temperatures would result in a low fault rate within the intended ageing period (two years). The determination of the electrical and environmental ageing conditions during the preliminary work is described in detail in (Mladenovic \& Weindl, Determination of the Environmental Conditions for the Accelerated Ageing of MV-PILC Cables, 2009).

\subsection{Measurement techniques}

Of the greatest importance for the ageing experiments are, beside the selection of ageing parameters, the measurements of the ageing voltage, the cable conductor temperature, the leakage currents (mainly capacitive) through the cable insulation, the environmental temperature and measurements of the diagnostic parameters. In Figure 11 a partial overview over some ICAAS components is shown.

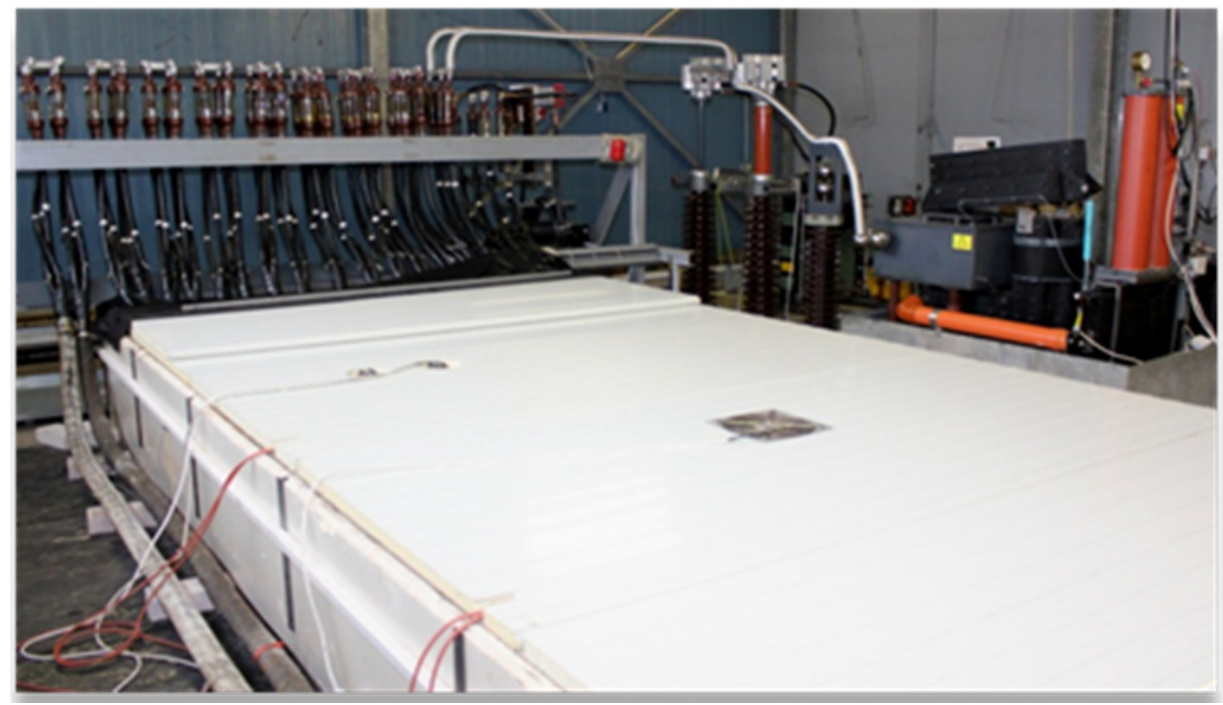

Figure 11. Partial overview over central components of the ICAAS system (transformers for voltage and current generation, overvoltage protection, rectifiers, etc.) and cable samples

Within the project period, several diagnostic measurement techniques have been developed, optimized and performed on each cable sample. Measurements of the dissipation factor on $50 \mathrm{~Hz}$, (Freitag C., to be published), with an accuracy of better then $10^{-5}$, as well as partial discharges are performed regularly in pre-defined time intervals (at least daily). Measurements of return voltage and polarization /depolarization currents have been carried out several times during complete ageing period. 
The initial condition of all cable samples was documented using PD analysis, $\tan (\delta)$ measurements and return voltage measurements (RVM), (Mladenovic \& Weindl, IEEE Electrical insulation Magazine, 2012). The resulting data are to be used as reference indicators for the later measurements. Anyway, the measurement of the PD is unique due to its local character, but should be correlated with measurements indicating the general cable condition like $\tan \delta$. However, a direct comparison of the measurement values is not possible due to their complex and not negligible dependency on environmental and test parameters, (Weindl, Mladenovic, Scharrer, \& Patsch, 2010) (Mladenovic \& Weindl, Dependencies of the PD- and $\tan (\delta)$-Characteristics on the Temperature and Ageing Status of MV PILC Cables, 2011) (Mladenovic \& Weindl, Dependency of the Dissipation Factor on the Test-Voltage and the Ageing Status of MV PILC Cables, 2011) (Mladenovic \& Weindl, Comparison of the parametric Partial Discharges and Dissipation factor Characteristics of MV PILC Cables, 2012). For this reason series of parametric studies under controlled test conditions were made, with the aim of documenting the dependence of $\tan \delta, \mathrm{PD}$ and return voltage on the cable condition, test voltage and cable temperature. In the following, some characteristic profiles of the dissipation factor and PD for different ageing groups will be presented and discussed.

\section{Parametric studies}

The measurements, which enable the analyses of the diagnostic parameters dependency on the test and the cable conditions, were accomplished under defined and monitored environmental conditions, at the network frequency of $50 \mathrm{~Hz}$, at selective test voltages in the range from $0.4 U_{n}$ to $2.2 U_{n}$ and within a temperature range from $10^{\circ} \mathrm{C}$ to over $90^{\circ} \mathrm{C}$. All measured values of the dissipation factor are presented in a normalized form of $\tan (\delta) / \tan (\delta)_{n}$, where $\tan (\delta)_{n}$ is the measured value on brand new (reference) cable at room temperature.

\subsection{Parametric studies of the dissipation factor}

Initial parametric study has pointed out three characteristic profiles of the dissipation factor, as shown in Figure 12. The occurrence of the resonant temperatures were dominant for unused but stored cables, since strong temperature dependencies were more related for cables with a long operation history.

According to Figure 6, a slight increase of the $\tan \delta$ in the region of $30-40^{\circ} \mathrm{C}$ in Figure 12 a) and b) could be interpreted as an optimal temperature for particular polarization processes, and temperature dependent profiles as a dominancy of $\tan \delta_{\text {con }}$. Differing to a temperature dependency that cannot be used as a diagnostic criterion (but must be considered), it is often assumed, that avoltage dependency is related to ionization processes and PD activity.

After approximately 6 weeks of artificial ageing the measurement procedure was repeated. The results are shown in Figure 13, respectively to Figure 12. The effects of the ageing on the absolute value of the dissipation factor are readily identifiable. Its increase is more intensive for cables with longer operation history, Figure $13 \mathrm{c}$ ). Moreover, the resonances are not 


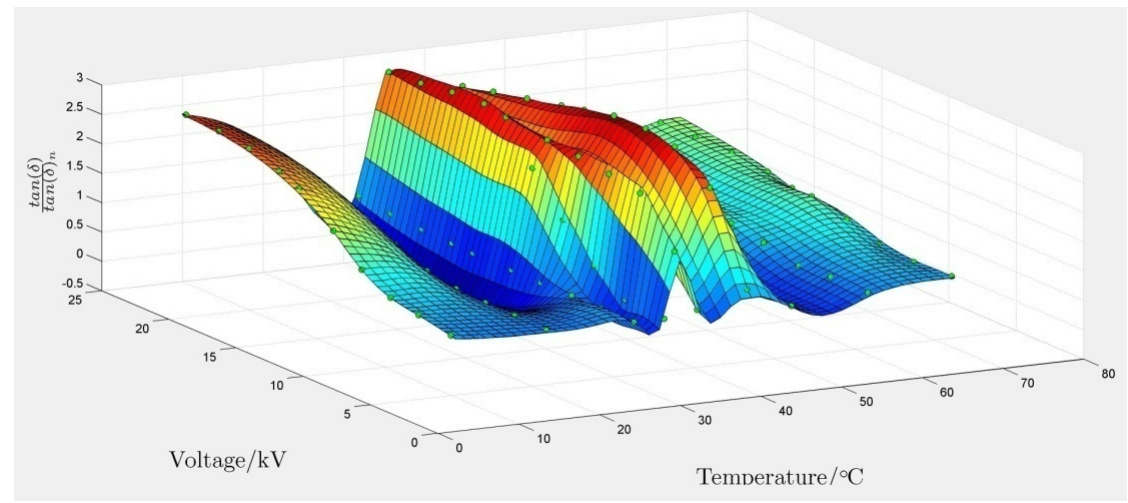

(a)

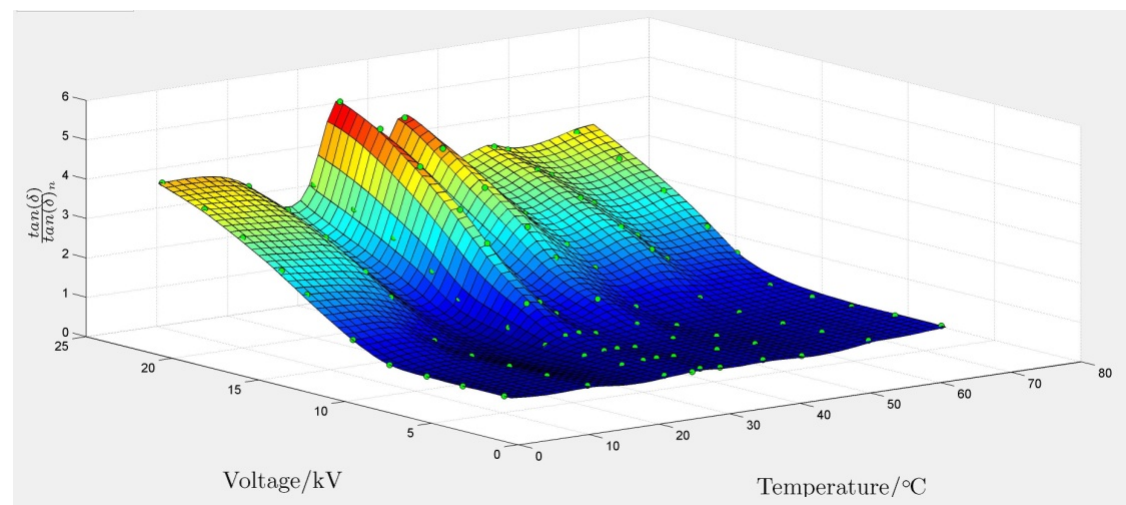

(b)

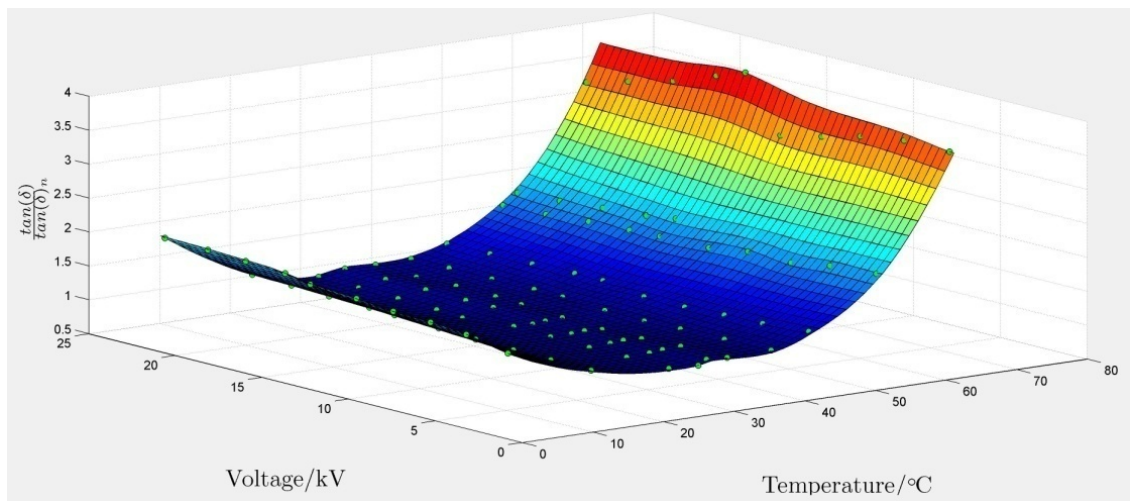

(c)

Figure 12. Selected initial profiles of $\tan \delta$ showing a resonant temperature region (a) and the voltage and temperature dependency for the different cables 


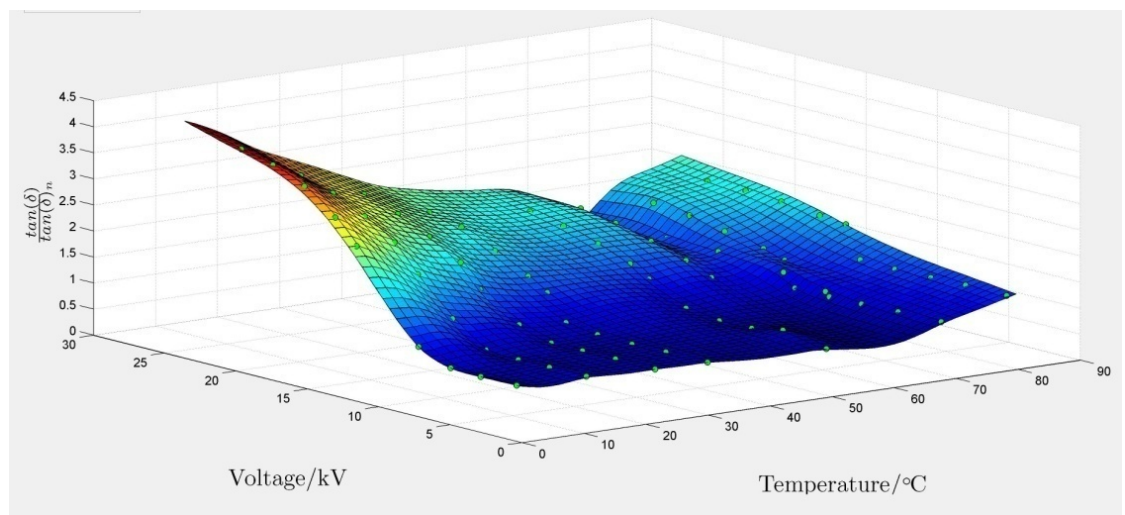

(a)

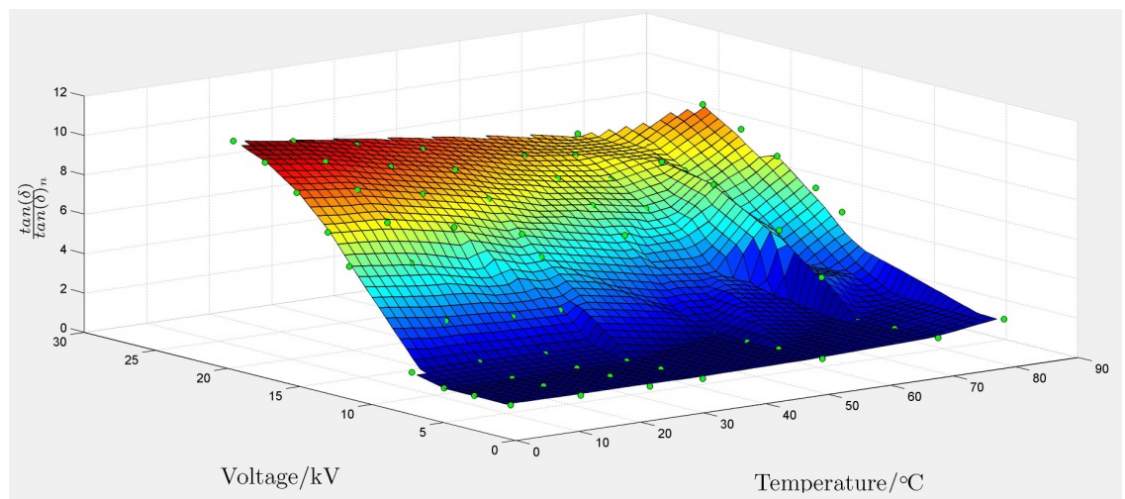

(b)

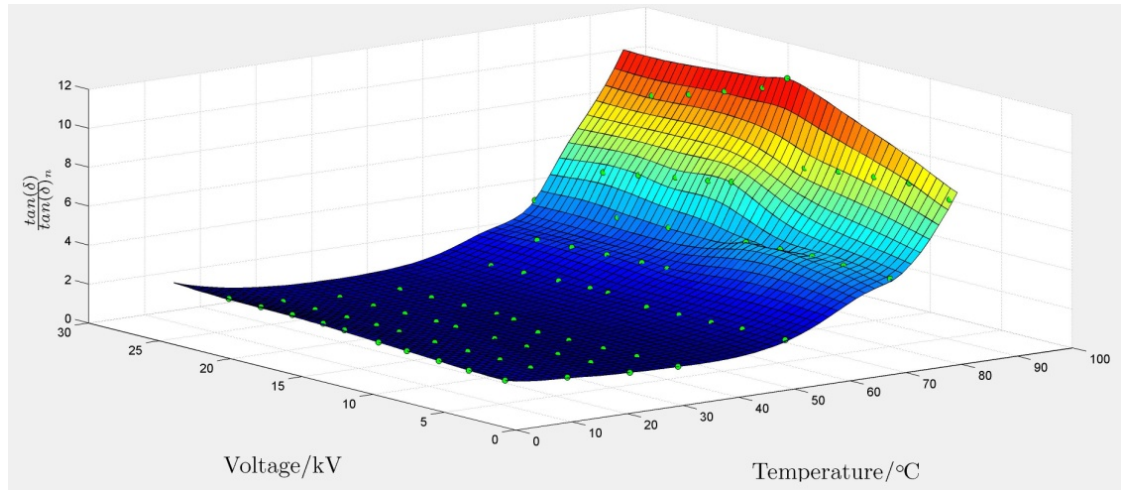

(c)

Figure 13. $\tan (\delta)$ profiles from Figure 12 after six weeks of ageing 
present in the same way as in Figure 12 a) and b). Since these cables have no service history (brand new and 10 years stored cable, respectively), presence of the voids at the beginning of the experiment can be assumed. During the ageing process, mass allocation through the temperature variation proceeds and could lead to the grouping of the voids and fast failure or voids releasing in terminations, as it was shown in (Mladenovic \& Weindl, Determination of the Environmental Conditions for the Accelerated Ageing of MV-PILC Cables, 2009). In further studies the PD activity, simultaneously measured to the $\tan \delta$, and the corresponding portion of losses will be presented.

\subsection{Parametric studies of PD}

Before PD profiles for specific cables are discussed, it is of the significant importance to affirm the evaluation and weighting of the single PD values out of the numerous impulses within one single measurement. For example, in Figure 14 two very different PD profiles from the same measurement cycle are presented. PD values are hereby evaluated from the impulses with highest repetition rate Figure 14 a) or from the average of the 50 maximal values Figure $14 \mathrm{~b}$. In order to determine the profile which represents the "real" PD activity in a better way, each single measurement has to be analyzed.

In Figure 15 single measurements for voltages $U_{0}$ up to $2,2 \cdot U_{0}$ with the step $0,2 \cdot U_{0}$ and variable temperatures are presented. Concerning the region of high temperatures, where is the deviation between figures a) and b) (Figure 14) the most significant, and comparing them to the single measurements shown in Figure 15, it can be concluded that better correlation of the profiles is reached by a calculation as shown in Figure $14 \mathrm{~b}$ ). Moreover, the analyses of other PD measurements were used to confirm this experimental thesis.

Finally, in the Figure 16 and Figure 17 PD-Temperature-Voltage profiles are shown respectively to the dissipation factor profiles in Figure 12 and Figure 13. It is obvious that a temperature region with amplified PD activity can be detected. Besides, only very intensive PD activity with a high density could cause losses within the material that would be recognizable in total dissipation losses. Due to the low absolute value of the initial dissipation factor this is visible by brand new cables, Figure 12 a) and Figure 16 a).

On the other hand, less intensive PDs in case Figure 16 b) and c) do not leave some obvious marks on the total dielectric losses in Figure 12 b) and c). Moreover, an amplified PD activity is present by brand new and stored-unused cable sample, what could confirm the assumption of the void presence, as mentioned before.

After six weeks of artificial ageing, there was a significant development of the PD activity, especially in the region of high temperatures. Anyway, it cannot be stated that areas 
with maximal PD activity correspond to those of highest dissipation losses. For example, very strong PD activity is present in the area of higher temperatures and voltages in Figure $17 \mathrm{~b}$ ). On the other hand, the dissipation losses of this cable show a dominant voltage dependency and almost no temperature dependency except on high voltages, whereby the maximal value lay in the region of low temperatures - differing therefore to PDs.

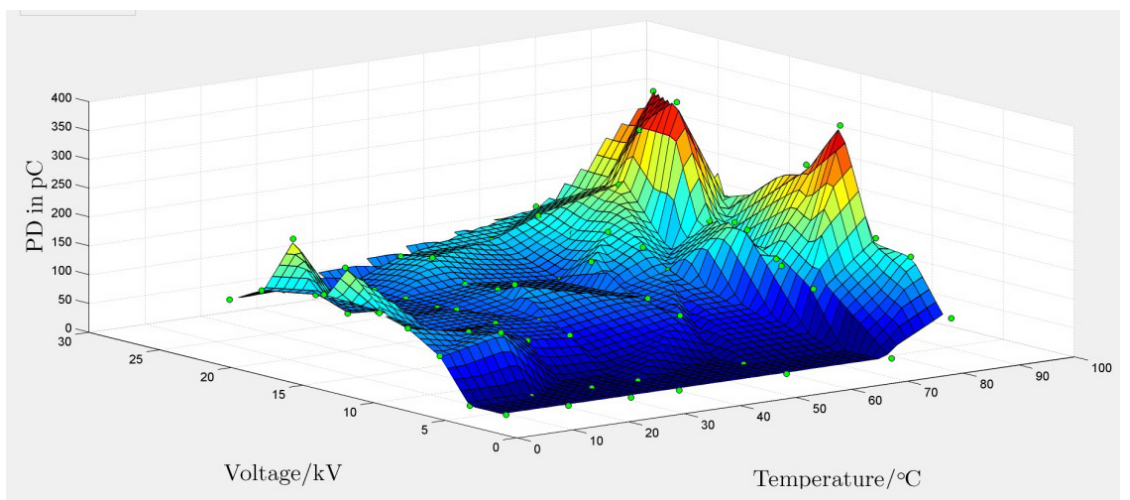

(a)

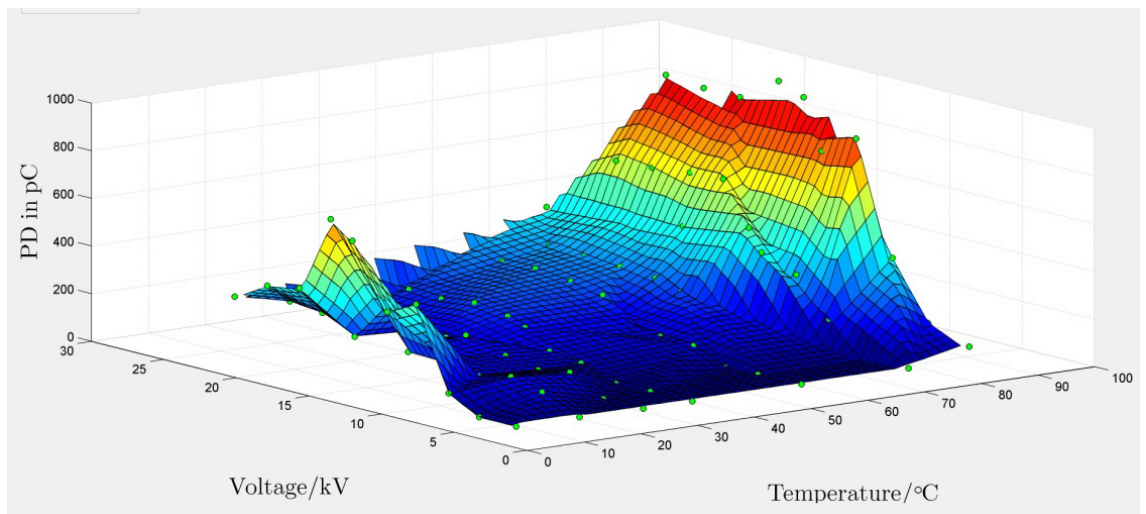

(b)

Figure 14. Two different PD profiles calculated from the same measurement cycle a) evaluated from the values with the highest repetition rate and $b$ ) evaluated from the average of the 50 maximal PD impulses 


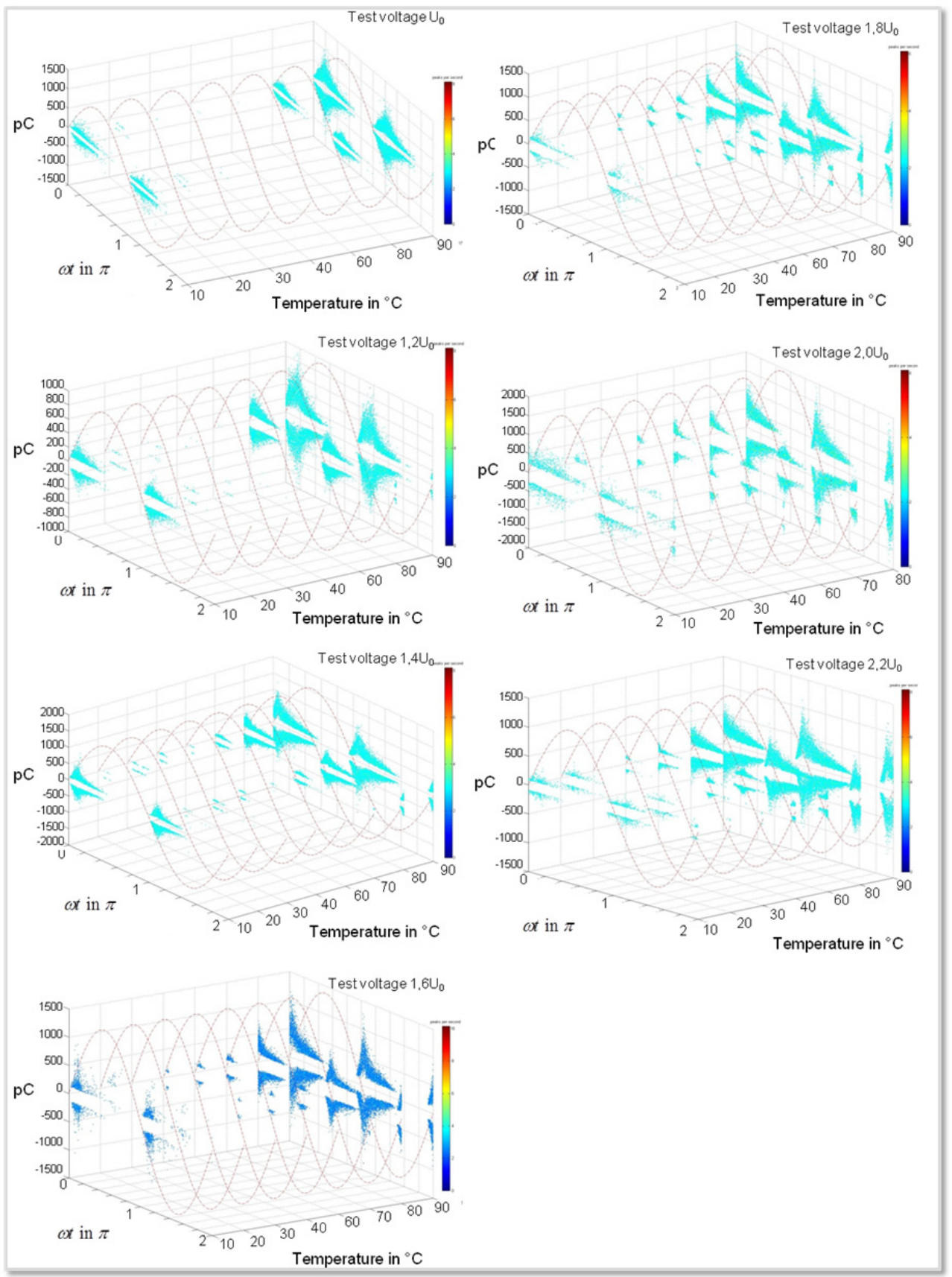

Figure 15. Background of PD profiles in Figure 14 - single PD measurements for variable test-voltages and temperatures 


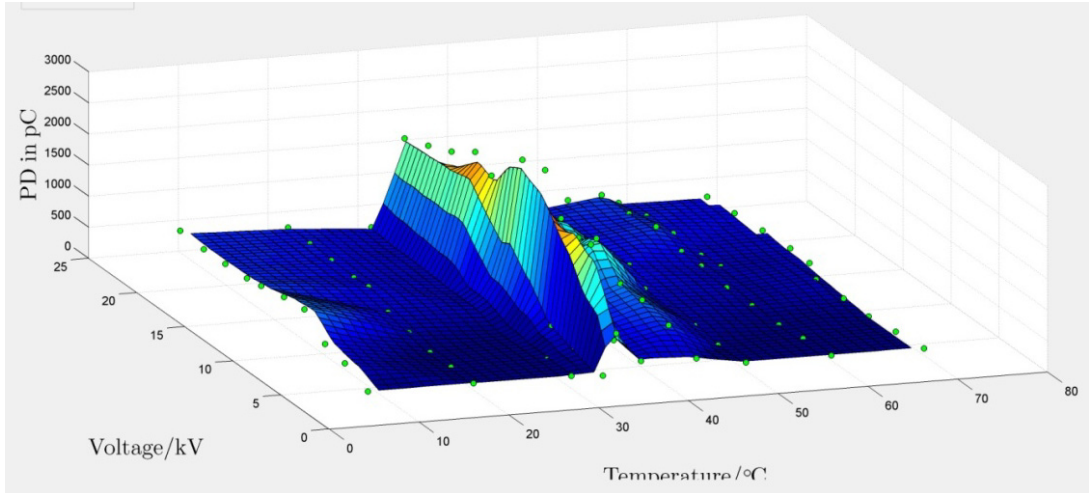

(a)

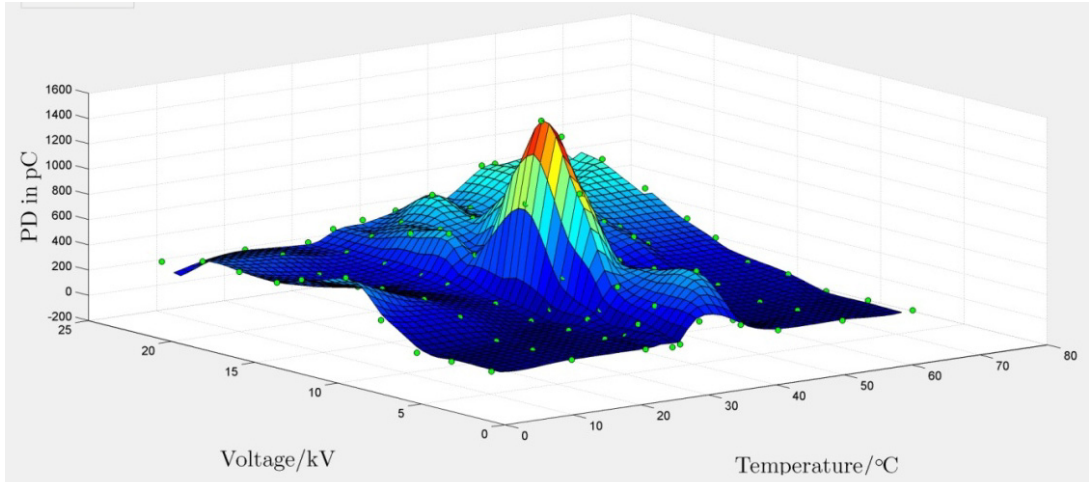

(b)

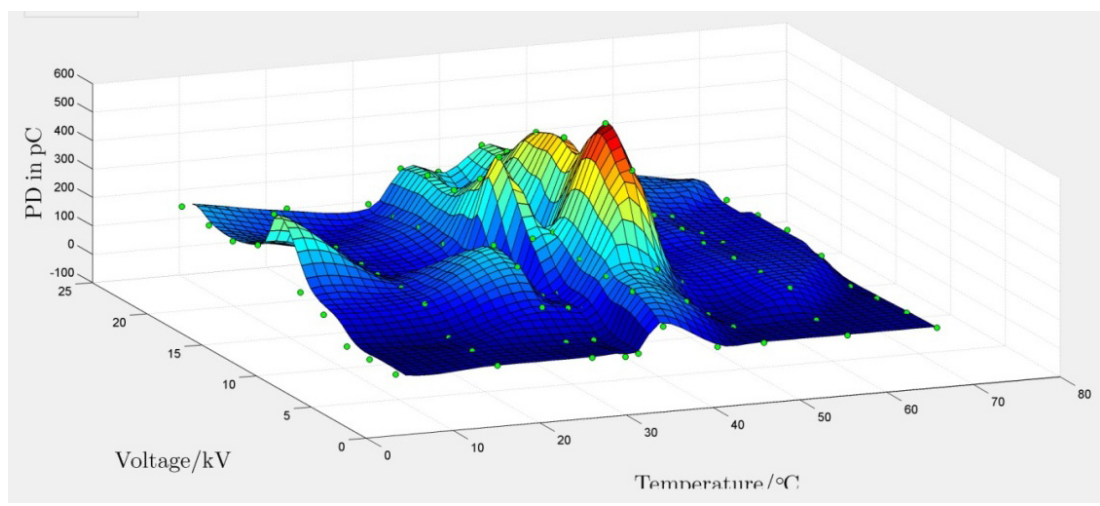

(c)

Figure 16. PD profiles simultaneously measured to the $\tan \delta$ acquisition shown in Figure 12 


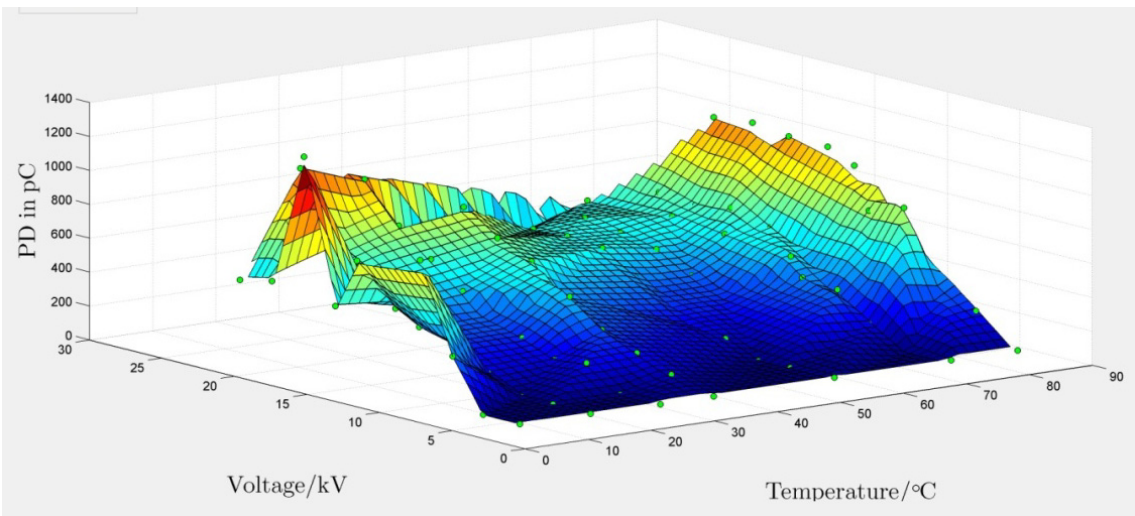

(a)

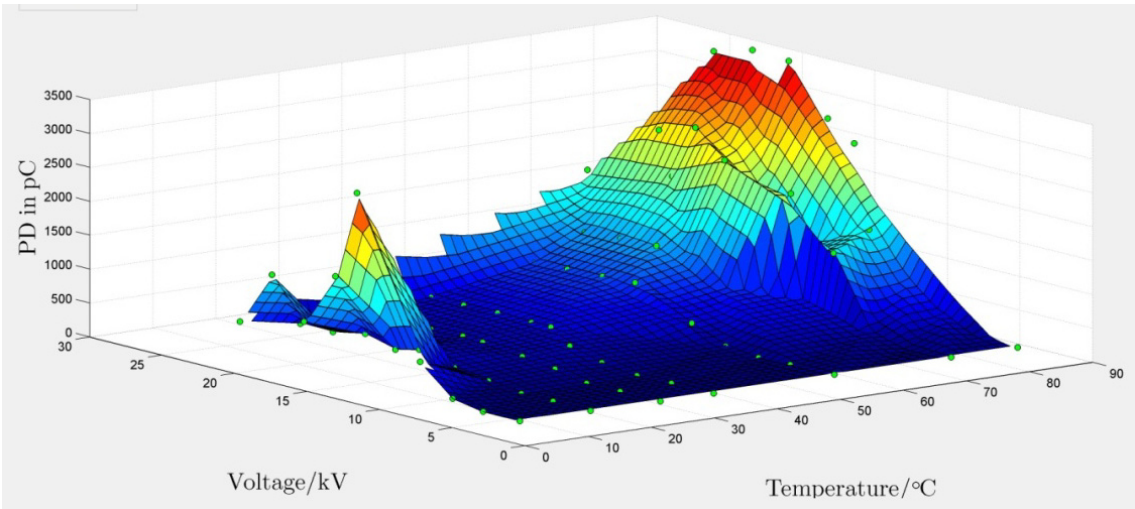

(b)

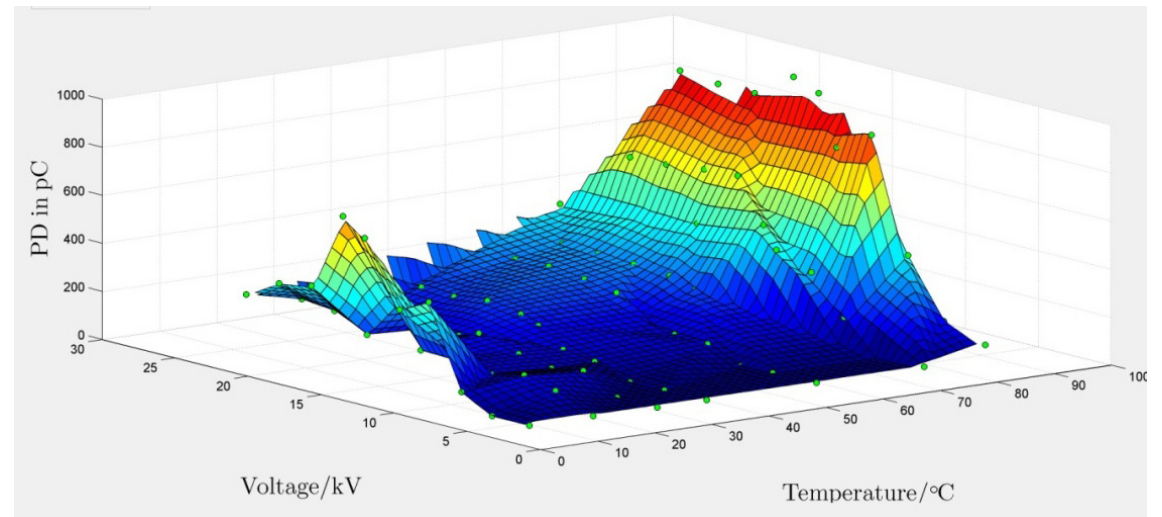

(c)

Figure 17. PD profiles simultaneously measured to the $\tan \delta$ shown in Figure 13 


\section{Failure distribution over diagnostic parameters}

Concerning a failed cable group from the same generation the Weibull distribution has been calculated. The Weibull plots in figure 4 show the distributions of cable failures over the normalized dissipation factor for variable test conditions. It can be noticed that the test voltage does not influence the Weibull curves significantly. Also, there is no strong curve deviation comparing the Weibull plot of one cable generation to all failed cables. The dominating influence factor is the temperature, showing more suitable test (diagnostic) conditions in higher temperature regions due to a better allocation of the values.

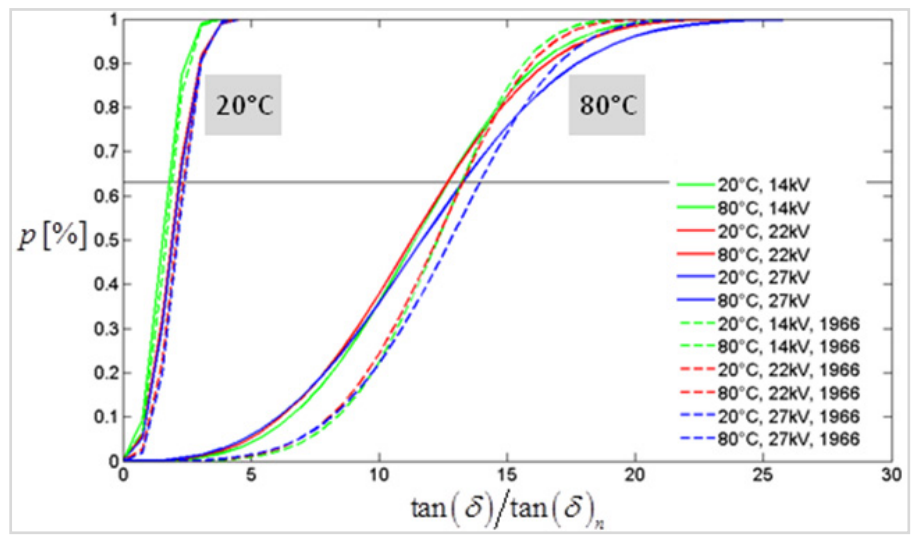

Figure 18. Weibull plots for variable tests conditions shown for all failed cables and one cable generation

Nevertheless, experimental results have also shown that temperatures lower than $20{ }^{\circ} \mathrm{C}$ are suitable for diagnostic measurements, too. Anyway, regarding to Figure 18 and Figure 19, the critical $\tan (\delta) / \tan (\delta)_{n}$-interval measured at $20^{\circ} \mathrm{C}$ is in the region of $1,8-2,4$, and at $80^{\circ} \mathrm{C}$ it is within 13-14.

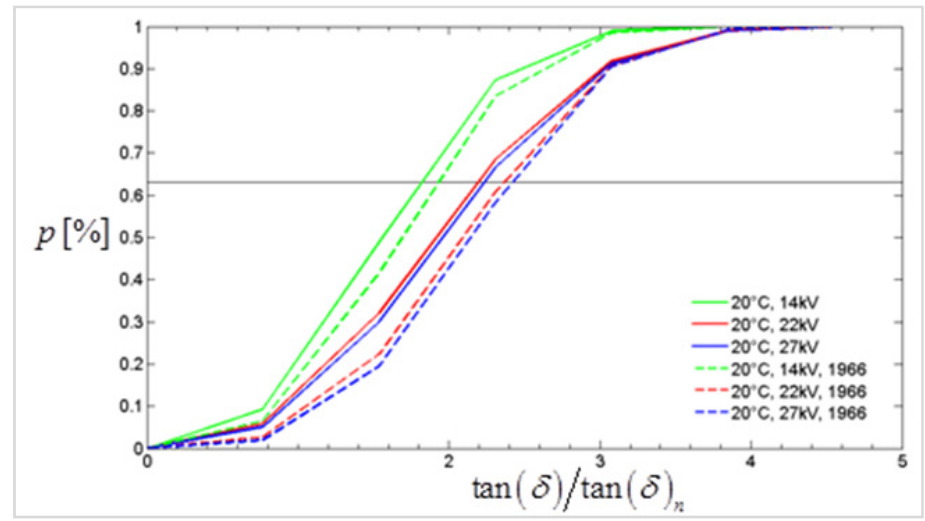

Figure 19. Weibull plot for $20^{\circ} \mathrm{C}$, variable test-voltage and for all failed cables or one cable generation 
Finally, the difficulty of the data analyzing of such a complex data collection is only indicated. In principal, in order to fit the most suitable distribution function and to determine the most probable remaining lifetime of the sample, the data must be carefully and precisely selected. Thereafter, it is possible to evaluate parameters of the ageing models, ageing factor and as a final point to apply these results in field measurements. In this way the cables condition can be estimated and life-consumption prognoses can be developed.

\section{Conclusion}

In a long-lasting ageing experiment, the ageing characteristics and diagnostic possibilities of the insulation system of MV PILC cables have been investigated. The study could be divided in several phases: developing, realization and verification of the entire ageing system (ICAAS) and its hardware and software components; selection of the cable samples and installation in ICAAS; selection of the ageing parameters; ageing experiment with regular measurements of the diagnostic parameters; regular parametric studies on the $\tan \delta$, PD, RVM, PDC in different stages of the ageing process; correlation between electrical, environmental and condition parameters; chemical analyses of the mass and paper samples; developing of the ageing/life models; reliability analyses, etc.

In the presented chapter dependencies of diagnostic parameters, like the PD and the tan $\delta$ characteristics are presented and discussed. The temperature region $20^{\circ} \mathrm{C}$ to $40^{\circ} \mathrm{C}$ is indicated as mainly inappropriate for measurements of cable's electrical properties and therefore diagnostic studies. PD diagnostics deliver a unique information with a mostly local character and should be executed and interpreted independently to other diagnostic measurements since considerable correlations between PD activity and tan $\delta$ profiles cannot be stated.

Additionally, Weibull plots for identical ageing-groupsof cables on different temperatures $\left(20^{\circ} \mathrm{C}\right.$ and $\left.80^{\circ} \mathrm{C}\right)$ are shown, and the characteristic tan $\delta$ values are pointed out.

Finally, one of the major future research objectives is and will be the further interpretation and development of theoretical models describing the correlations between the data from the determined sophisticated knowledge databank. Moreover, the developed models and correlations will be verified through already started diagnostic field studies.

\section{Author details}

I. Mladenovic and Ch. Weindl

University of Erlangen-Nuremberg, Institute of Electrical Power Systems, Germany

\section{Acknowledgement}

The authors would like to thank the following cooperating companies for the financial and organizational support of the entire project: N-ERGIE AG (Germany), N-ERGIE Netz GmbH (Germany), N-ERGIE Service GmbH (Germany), Bayerische Kabelwerke AG (Germany). 


\section{References}

1407, I. S. (1998). IEEE Trial-Use Guide for Accelerated Aging Tests for Medium-Voltage Extruded Electric Power Cables Using Water-Filled Tanks.

(2010). Retrieved from www.wikieduc.ch: www.wikieduc.ch/images/7/71/Isolierstoffe.doc

400, I. S. (2001). "IEEE Guide for Field Testing and Evaluation of the Insulation of Shielded Power Cable Systems.

400.2, I. S. (2004). IEEE Guide for Field Testing of Shielded Power Cable Systems Using Very Low Frequency (VLF).

60270, I. (2000). High-voltage test techniques - Partial discharge measurements.

62478, I. (2011). High voltage test techniques - Measurement of partial discharges by electromagnetic and acoustic methods "Proposed Horizontal Standard".

Ambikairajah, R., Phung, B. T., Ravishankar, J., Blackburn, T. R., \& Liu, Z. (2010). Smart Sensors and Online Condition Monitoring of High Voltage Cables for the Smart Grid. roceedings of the 14 th International Middle East Power Systems Conference (MEPCON'10), (p. ID 289). Cairo University, Egypt.

Bartnikas, R. (2002, October). Partial Discharges - Their Mechanism, Detection and Measurement. IEEE Transactions on Dielectrics and Electrical Insulation, 9 (5), pp. 763-808.

Bayer, M., Boeck, W., Möller, K., \& Zaengl, W. (1986). Hochspannungstechnik - Theoretische und praktische Grundlagen für die Anwendung. Soringer.

Bennett, G. E. (October 1957). Paper Cable Saturants: European Preferences and Selection. AIEE Summer General Meeting, (pp. 687-696). Montreal, Canada.

Boltze, M., Markalous, S., Bolliger, A., Ciprietti, O., \& Chiu, J. (2009). On-line partial discharge monitoring and diagnosis at power cables. 76th Annual International Doble Client Conference.

Colebrook, M. (n.d.). Retrieved from Green spirit: www.greenspirit.org.uk/resources/cellulose.gif

Cuppen, A. N., Steennis, E. F., \& van der Wielen, P. C. (2010). Partial Discharge Trends in Medium Voltage Cables measured while in-service with PDOL. Transmission and Distribution Conference and Exposition, 2010 IEEE PES. New Orleans, LA, USA.

Densley, J. (2001, January/February). Ageing mechanisms and Diagnostics for Power Cables - An Overview. IEEE Electrical Insulation Magazine, 17 (1), pp. 14-22.

Dr.-Ing. Weindl, C., \& Dipl.-Ing. Mladenovic, I. (2009). Bestimmung von Restlebensdauer von Massekabeln anhand einer Teilentladungs- und $\tan (\delta)$-Diagnose. Diagnostik elektrischer Betriebsmittel - ETG Kongress. Dusseldorf, Germany.

Emsley, A. M., \& Stevens, G. C. (1994). Kinetics and mechanisms of the low-temperature degradation of cellulose. Cellulose (1), 26-56.

FGH - Forschungsgemeinschaft für Elektrische Anlagen und Stromwirtschaft e. V.. (2006). Zustandsdiagnose von Papiermasse-Kabelanlagen in Verteilungsnetzen. Technischer Bericht 300, Mannheim.

Freitag, C. (to be published). Entwicklung und Anwendung optimierter Verfahren der Verlustfaktorbestimmung zur Diagnose von Mittelspannungskabeln (working title). Doktoral Thesis, University of Erlangen-Nuremberg, Erlangen. 
Freitag, C. (2008). Entwicklung und Implementierung eines Steuerungs-, Regelungs- und Messsystems zur Realisierung einer automatisierten Versuchsanlage für die beschleunigte Alterung von Mittelspannungskabeln. Diploma Thesis, University of Erlangen-Nürnberg, Erlangen, Germany.

Freitag, C., Mladenovic, I., \& Weindl, C. (2010). Fully Automated MV Cable Monitoring and Measurement System for Multi-Sample Acquisition of Artificial Aging Parameters. ICREPQ. Spain.

Freitag, C., Weindl, C., \& Mladenovic, I. (2011). On-Line Cable Diagnostic Possibilities in an Artificial Aging Environment. ICREPQ 2011. Spain.

Glaubitz, W., Postler, H., Rittinghaus, D., Seel, G., Sengewald, F., \& Winkler, F. (1989). Kabel und Leitungen für Starkstrom - Teil 2 (4. ed.). (L. H. Stubbe, Ed.) Germany: Siemens Aktiengesellschaft.

High Voltage - VLF Hipot Instruments. (n.d.). Tan $\delta$ (Delta) Cable Testing.

Kock, J. d., \& Strauss, C. (2004). Practical Power Distribution for Industry (1 ed.). (Newnes, Ed.) Oxford, UK: Elsevier.

Küchler, A. (2009). Hochspannungstechnik. Berlin: Springer.

Kuhnert, Wieznerowicz, \& Wanser. (1997). Eigenschaften von Energiekabeln und deren Messung (2. Edition ed.). Frankfurt am Main, Germany: VWEW.

Lemke, E. (2008). Guide for partial discharge measurements in compliance to IEC 60270. Germany. Mladenovic I., W. C. (2009). New System for MV-Cable ageing under controlled conditions. Congrès international des Réseaux électriques de Distribution 2009, CIRED. Tschech Republic.

Mladenovic, I. (2012, to be published). Determination of the Remaining Lifetime of PILC cables based on $P D$ and $\tan (\delta)$ diagnostics. Doctoral Thesis, University of Erlangen-Nuremberg, Erlangen.

Mladenovic, I., \& Weindl, C. (2012, January/February). Artificial Aging and Diagnostic Measurements on Medium-Voltage, Paper-Insulated, Lead-Covered Cables. IEEE Electrical insulation Magazine, 28 (1), pp. 20-26.

Mladenovic, I., \& Weindl, C. (2012). Comparison of the parametric Partial Discharges and Dissipation factor Characteristics of MV PILC Cables. IEEE International Symposium on Electrical Insulation - ISEI 2012. Puerto Rico.

Mladenovic, I., \& Weindl, C. (2011). Dependencies of the PD- and $\tan (\delta)$-Characteristics on the Temperature and Ageing Status of MV PILC Cables. Electrical Insulation Conference EIC. Annapolis, USA.

Mladenovic, I., \& Weindl, C. (2011). Dependency of the Dissipation Factor on the TestVoltage and the Ageing Status of MV PILC Cables. Jicable11. Versailles, France.

Mladenovic, I., \& Weindl, C. (2008). Determination of the Characteristic Life Time of Paperinsulated MV-Cables based on a Partial Discharge and $\tan (\delta)$ Diagnosis. 14th International Power Electronics and Motion Control Conference EPE-PEMC. Poland.

Mladenovic, I., \& Weindl, C. (2009). Determination of the Environmental Conditions for the Accelerated Ageing of MV-PILC Cables. 9th International Conference on Properties and Applications of Dielectric Materials, ICPADM. China.

Mladenovic, I., \& Weindl, C. (2010). Development of the Partial Discharges Inception Voltage for Different Sets of Pre-Aged PILC Cable Samples. International Symposium on Electrical Insulation, ISEI. San Diego, USA. 
Mladenovic, I., \& Weindl, C. (2009). ICAAS - Integrated System for lasting Accelerated Aging of MV Cables, Data Monitoring and Acquisition. IEEE Conference on Electrical Insulation and Dielectric Phenomena 2009, CEIDP. Virginia Beach, USA.

Mladenovic, I., \& Weindl, C. (2010). Influence of the thermal stress on the diagnostic parameters of PILC cables. International Conference on Condition Monitoring and Diagnosis, CMD. Japan.

Neimanis, R., \& Eriksson, R. (2004, January). Diagnosis of moisture in oil/paper distribution cables - Part I: Estimation of moisture content using frequency-domain spectroscopy. IEEE Transactions on Power Delivery, 1, pp. 9-14.

Niemeyer, L. (1995). A Generalized Approach to Partial Discharge Modeling. IEEE Transactions on Dielectrics and Electrical Insulation, 2 (4), 510-528.

Petzold, F., \& Gulski, E. (2006). Experiences with PD offline Diagnosis on MV cables Knowledge Rules for Asset Decisions. MNC-CIRED, Asia Pacific Conference on TED Asset Management.

Petzold, F., \& Zakharov, M. (2005). PD Diagnosis on Medium Voltage Cables with Oscillating Voltage (OWTS). Power Tech. St. Petersburg, Russia.

Robinson, G. (1990, March). Ageing characteristics of paper-insulated power cables. Power Engineering Jurnal, pp. 95-100.

Soares, S., Caminot, G., \& Levchik, S. (1995). Comparative study of the thermal decomposition of pure cellulose and pulp paper. Polymer Degradation and Stability, 49, pp. 275-283.

Stanka, M. (2011). Alterungsmechanismen ausgesuchter Isoilierstoffe für Betriebsmittel der Hoch- und Mittelspannungstechnik. Diploma Thesis, University of Erlangen-Nuremberg, Erlangen.

Steennis, E. F., Ross, R., van Schaik, N., Boone, W., \& van Aartrijk, D. (2001). Partial discharge diagnostics of long and branched medium-voltage cables. IEEE 7 th International Conference of Solid Dielectrics - ICSD. Eindhoven, the Netherlands.

Tellier, R. (1983). Hundert Jahre Energiekabel - Rückschau und Ausblick. Elektrizitätswirschaft, 3.

Tian, Y., Lewin, P. L., Wilkinson, J. S., Sutton, S. J., \& Swingler, S. G. Continuous Online Monitoring of Partial Discharges in High Voltage Cables.

http://eprints.soton.ac.uk/38246/1/2797.pdf.

Unsworth, J., \& Mitchell, F. (1990, August). Degradation of Electrical Insulating Paper Monitored with High Performance Liquid Chromatography. IEEE Transactions on Electrical Insulation, 25 (4), pp. 737-746.

Weindl, C. (2012). Verfahren zur Bestimmung des Alterungsverhaltens und zur Diagnose von Betriebsmitteln der elektrischen Energieversorgung. University of Erlangen-Nuremberg, Erlangen.

Weindl, C., Mladenovic, I., Scharrer, T., \& Patsch, R. (2010). Development of the p-factor in an Accelerated Ageing Experiment of the MV PILC Cables. 10th International Conference on Solid Dielectrics, ICSD. Germany.

Wouters, P. A., van der Wielen, P. C., Veen, J., Wagenaars, P., \& Steennis, E. F. (2005). Effect of Cable Load Impedance on Coupling Schemes for MV Power Line Communication. IEEE Transactions on Power Delivery, Vol. 20, No. 2, April 200, 20 (2), 638-645. 